\title{
La anulación del Plan de Protección del Corredor Litoral de Andalucía por el Tribunal Superior de Justicia de Andalucía: ¿nuevas dificultades en la planificación territorial de Andalucía?
}

\section{The annulment of the Protection Plan of the Corredor Litoral de Andalucia by the Superior Court of Justice of Andalucia: new difficulties in the territorial planning of Andalucia?}

\author{
Esther Rando Burgos \\ Universidad de Málaga \\ erando@uma.es
}

\section{NOTA BIOGRÁFICA}

Doctora en Derecho por la Universidad de Málaga. Licenciada en Derecho y Licenciada en Ciencias del Trabajo por la Universidad de Málaga. Diplomada en Ordenación del Territorio. Abogada. Profesora de Derecho Administrativo de la Universidad de Málaga. Sus líneas de investigación se centran en el ámbito de la ordenación del territorio, el urbanismo y el medio ambiente.

\section{RESUMEN}

Las recientes Sentencias del Tribunal Superior de Justicia de Andalucía que anulan el Plan de Protección del Corredor Litoral de Andalucía, tras dos años de vigencia y, nuevamente, los motivos de tales resoluciones judiciales, no desconocidos para esta Comunidad Autónoma que ya en 2015 se enfrentaba a la nulidad de otro de sus instrumentos de planificación territorial, el Plan de Ordenación del Territorio de la Costa del Sol Occidental de Málaga, hacen necesaria una nueva reflexión sobre la importancia que la tramitación y el estricto cumplimiento de las cuestiones formales en la aprobación de los instrumentos de planificación territorial tienen en la práctica jurídica.

\section{PALABRAS CLAVE}

Control judicial; ordenación del territorio; procedimiento administrativo; gobierno en funciones.

\begin{abstract}
The recent Judgments of the Superior Court of Justice of Andalucia that not strangers annul the Protection Coast Andalucia Plan, after two years of validity and, again, the motives of such legal rulings, for this Autonomous region that in 2015 was already facing the nullity of other of its instruments of territorial planning, the Plan of Town and country planning of the Western Costa del Sol of Malaga, make a new reflection necessary on the importance that the procedure and the strict fulfillment of the formal questions in the approval of the instruments of territorial planning have in practice juridical.
\end{abstract}

\section{KEYWORDS}

Judicial control; land planning; administrative procedure; government in office.

\section{SUMARIO}

1. INTRODUCCIÓN. 2. PLAN DE PROTECCIÓN DEL CORREDOR LITORAL DE ANDALUCÍA. 2.1. ANTECEDENTES. 2.2. PRINCIPIOS Y OBJETIVOS. 2.3. ÁMBITO TERRITORIAL. 2.4. NATURALEZA 
REALA. Nueva Época - N. 10, Octubre 2018 - ISSN: 1989-8975 - DOI: 10.24965/reala.v0i10.10518 - [Págs. 109-131]

La anulación del Plan de Protección del Corredor Litoral de Andalucía por el Tribunal Superior de Justicia de Andalucía: ¿nuevas...

Esther Rando Burgos

JURÍDICA Y RELACIÓN CON OTROS INSTRUMENTOS DE PLANIFICACIÓN TERRITORIAL. 2.5. LA TRAMITACIÓN DEL PPCLA DE CONFORMIDAD CON LA LOTA. 2.6. EL PROCESO DE TRAMITACIÓN DEL PPCLA. 2.6.1. Decreto-ley 5/2012, de 27 de noviembre, de medidas urgentes en materia urbanística y para la protección del litoral. 2.6.2. Formulación. 2.6.3. Información pública. 2.6.4. Decreto-ley 15/2014, de 25 de noviembre. 2.6.5. Aprobación y entrada en vigor. 2.7. IMPUGNACIÓN DEL DECRETO-LEY 5/2012 ANTE EL TRIBUNAL CONSTITUCIONAL Y SENTENCIA DEL TRIBUNAL CONSTITUCIONAL 27/2016, DE 19 DE FEBRERO. 3. SENTENCIA DEL TRIBUNAL SUPERIOR DE JUSTICIA DE ANDALUCÍA, SALA DE LO CONTENCIOSO-ADMINISTRATIVO, DE 7 DE SEPTIEMBRE DE 2017, POR LA QUE SE DECLARA LA NULIDAD DEL PLAN DE PROTECCIÓN DEL CORREDOR LITORAL DE ANDALUCÍA. 3.1. CUESTIONES PREVIAS. 3.2. RESUMEN DE LA SENTENCIA. 3.3. PRONUNCIAMIENTO DEL TRIBUNAL SUPERIOR DE JUSTICIA DE ANDALUCÍA. 3.3.1. Sobre el marco jurídico de referencia. 3.3.2. Sobre la doctrina jurisprudencial fijada por el Tribunal Supremo y la interpretación del concepto «despacho ordinario de asuntos». 3.3.3. Sobre la interpretación de la Sala de lo Contencioso-administrativo del TSJ de Andalucía. 3.3.4. Sobre la posible concurrencia de razones de urgencia o de interés general en la aprobación del PPCLA. 4. REFLEXIONES FINALES. 5. BIBLIOGRAFÍA.

\section{INTRODUCCIÓN}

La aprobación en 2015 del Plan de Protección del Corredor Litoral de Andalucía ${ }^{1}$, supuso un paso significativo en el largo camino emprendido décadas atrás por esta Comunidad Autónoma con el firme objetivo de implantar y desarrollar la ordenación del territorio.

Precisamente el Plan de Protección del Corredor Litoral de Andalucía es el último instrumento de planificación territorial aprobado en la Comunidad Autónoma, al que anteceden el propio Plan de Ordenación del Territorio de Andalucía y un total de diecisiete Planes de Ordenación del Territorio de ámbito subregional vigentes $^{2}$, a los que se han de sumar otros cinco que se vienen redactado o tramitando ${ }^{3-4}$.

Sin duda, las cifras hablan por sí solas, una ingente labor que sitúa a Andalucía en una posición privilegiada en el marco comparado con otras Comunidades Autónomas.

El camino no ha sido fácil, como lo evidencia el tiempo que ha sido preciso para llegar hasta aquí. De ahí que el reciente varapalo que supone la nulidad del Plan de Protección del Corredor de Litoral de Andalucía, un instrumento de planificación clave para Andalucía, tras algo más de dos años de vigencia, y el motivo jurídico que determina tal decisión, centrado en una cuestión netamente formal, hace necesario volver a detenerse en la importancia de un riguroso y estricto cumplimiento de los trámites procedimentales en la fase de elaboración de los instrumentos so pena de nefastas consecuencias que no sólo atañen a la ordenación territorial sino que, directa o indirectamente, afectan a otras tantas funciones públicas.

Es por ello que se considera de enorme interés analizar el Plan de Protección del Corredor Litoral de Andalucía, su aparición, regulación e implantación en el escenario autonómico, para a partir de lo anterior, conocer la primera de las Sentencias que anulan el instrumento, al objeto de poder establecer unas primeras conclusiones en torno a sus consecuencias y la situación que, en general, presenta la planificación territorial andaluza.

1 Decreto 141/2015, de 26 de mayo, por el que se aprueba el Plan de Protección del Corredor Litoral de Andalucía (BOJA, núm. 139, de 20-07-2015).

2 Plan de Ordenación del Territorio de la Aglomeración Urbana de Granada; Plan de Ordenación del Territorio del Poniente de Almería; Plan de Ordenación del Territorio de la Sierra de Segura (Jaén); Plan de Ordenación del Territorio del Ámbito de Doñana; Plan de Ordenación del Territorio de la Bahía de Cádiz; Plan de Ordenación del Territorio del Litoral Occidental de Huelva; Plan de Ordenación del Territorio del Litoral Oriental-Axarquía (Málaga); Plan de Ordenación del Territorio del Levante de Almería; Plan de Ordenación del Territorio de la Aglomeración Urbana de Sevilla; Plan de Ordenación del Territorio de la Aglomeración Urbana de Málaga; Plan de Ordenación del Territorio de la Costa Noroeste de Cádiz; Plan de Ordenación del Territorio de La Janda; Plan de Ordenación del Territorio de la Aglomeración Urbana de Almería; Plan de Ordenación del Territorio del Campo de Gibraltar; Plan de Ordenación del Territorio de la Costa Tropical de Granada; Plan de Ordenación del Territorio del Sur de Córdoba; Plan de Ordenación del Territorio de la Aglomeración Urbana de Jaén.

3 Plan de Ordenación del Territorio de la Aglomeración Urbana de Huelva; Plan de Ordenación del Territorio de la Aglomeración Urbana de Córdoba; Plan de Ordenación del Territorio del Almanzora; Revisión del Plan de Ordenación del Territorio Bahía de CádizJerez; Plan de Ordenación del Territorio de la Costa del Sol Occidental de Málaga.

${ }^{4}$ En la página web de la Consejería de Medio Ambiente y Ordenación del Territorio de la Junta de Andalucía, puede consultarse la documentación de los diferentes instrumentos de planificación territorial de la Comunidad Autónoma, además de ofrecer otros datos de interés en relación con los mismos.

Disponible http://www.juntadeandalucia.es/medioambiente/site/portalweb/menuitem.6ffc7f4a4459b86a1daa5c105510e1ca/?vgne $x$ toid $=b 45 e 6 b 7 \mathrm{bf3d} 34510 \mathrm{VgnVCM} 2000000624 \mathrm{e} 50 \mathrm{aRCRD}$. 


\section{PLAN DE PROTECCIÓN DEL CORREDOR LITORAL DE ANDALUCÍA}

\subsection{Antecedentes}

La ordenación del territorio en Andalucía, formalmente, inicia su andadura con su inclusión como competencia exclusiva de la Comunidad Autónoma en el Estatuto de Autonomía ${ }^{5}$, en base a la atribución competencial del art. 148.1.3. ${ }^{a}$ de la Constitución Española, $\mathrm{CE}^{6-7}$.

Unos años más tarde, le seguiría la aprobación de la Ley 1/1994, de 11 de enero, de Ordenación del Territorio de Andalucía, para sucesivas menciones LOTA, marco legislativo que continua vigente. Es a partir de este momento, cuando Andalucía comienza paulatinamente a desarrollar esta función pública ${ }^{8}$, labor que continua en la actualidad.

En general, la ordenación del territorio presenta un conjunto de particularidades que hacen de ésta una función pública singular ${ }^{9}$ a lo que se une su carácter relativamente joven, cuestiones que explican que nos encontremos ante una materia que sigue pendiente de su definitiva consolidación, camino que, a la luz de la Sentencia objeto del presente trabajo y algunas otras, no está resultando fácil.

La ordenación del territorio, como otras competencias tales como turismo, urbanismo, medio ambiente, se desarrolla y concreta a través de la planificación. La planificación territorial se desarrolla según un orden lógico y estructurado que en el caso andaluz, está contemplado en la LOTA. Los planes territoriales no tienen tal entidad y autonomía para poder establecer sus propias directrices obviando el marco en que se desen-

5 El art. 13.8 de la Ley Orgánica 6/1981, de 30 de diciembre, de Estatuto de Autonomía para Andalucía, disponía la competencia exclusiva de la Comunidad Autónoma de Andalucía sobre «política territorial: ordenación del territorio y del litoral urbanismo y vivienda».

${ }^{6}$ El art. 148.1.3. ${ }^{a}$ de la CE, faculta a las Comunidades Autónomas a asumir, entre otras competencias, las relativas a «ordenación del territorio, urbanismo y vivienda».

7 De manera análoga, todas las Comunidades Autónomas, asumieron la competencia, comenzando con ello el desarrollo de esta función pública que apenas contaba con una base previa que les sirviera como soporte en este sentido. Sobre la aparición y evolución de la ordenación del territorio, vid. PÉREZ ANDRES, A. A. (1998): La ordenación del territorio en el estado de las autonomías, Marcial Pons, BENABENT F. DE CÓRDOBA, M. (2006): La Ordenación del Territorio en España: evolución del concepto y de su práctica en el siglo XX. Sevilla: Consejería de Obras Públicas y Transportes de la Junta de Andalucía y Universidad de Sevilla y HILDENBRAND SCHEID, A. (1996): Política de Ordenación del Territorio en Europa. Sevilla: Universidad de Sevilla. Consejería de Obras Públicas y Transportes.

8 Sobre la aparición y evolución de la ordenación del territorio en Andalucía pueden verse, entre otras, HILDENBRAND SCHEID, A. (2002): "La política territorial de la Junta de Andalucía (1982-2002). Análisis de su implementación, balance y propuestas". Ponencia XX Aniversario del Estatuto de Autonomía de Andalucía. Jornadas de Estudio organizadas por el Parlamento de Andalucía, Jerez de la Frontera, 6, 7 y 8 de marzo de 2002 y ZOIDO NARANJO, F. (2011): "Ordenación del territorio en Andalucía". Cuadernos Geográficos, núm. 47 (2010-2), págs. 189-221. De manera más reciente, GONZÁLEZ FUSTEGUERAS, M. A (2017): "Luces y sombras de la ordenación del territorio en Andalucía. Nuevas perspectivas", Práctica urbanística: Revista mensual de urbanismo, núm. 147 (Ejemplar dedicado a: La ordenación del territorio en Andalucía) y RANDO BURGOS, E. (2018a): Áreas de oportunidad y ordenación del territorio en Andalucía. Inédito, pendiente de publicación. Sevilla, Instituto Andaluz de Administración Pública. Junta de Andalucía.

${ }^{9}$ El carácter transversal de la ordenación del territorio y su gran amplitud, no han pasado desapercibidas. Entre las primeras Sentencias en ocuparse de su definición, que incorpora las que la anteceden, la STC 149/1991, de 4 de julio (BOE, núm. 180, de 2907-1991). En ella, el TC reconoce las escasas precisiones que sobre el concepto de ordenación del territorio se encuentran en nuestra doctrina y cita la STC 77/1984 que afirma que la ordenación del territorio «tiene por objeto la actividad consistente en la delimitación de los diversos usos a que pueda destinarse el suelo o espacio físico territorial». Por su parte, la define como "La ordenación del territorio es, efectivamente, más una política que una concreta técnica y una política, además, de enorme amplitud. La Carta Europea de Ordenación del Territorio, aprobada por la CEMAT (Conferencia Europea de Ministros de Ordenación del Territorio) el 23 de mayo de 1983, citada por muchos de los recurrentes, la define como "expresión espacial de la política económica, social, cultural y ecológica de toda sociedad"» y expresamente insiste en la amplitud que caracteriza a esta función pública, así establece que "Esa enorme amplitud de su ámbito propio evidencia que quien asume, como competencia propia, la ordenación del territorio, ha de tomar en cuenta, para llevarla a cabo la incidencia territorial de todas las actuaciones de los poderes públicos, a fin de garantizar de ese modo el mejor uso de los recursos del suelo y del subsuelo, del aire y del agua y el equilibrio entre las distintas partes del territorio mismo. Cuando todas esas actuaciones sobre un mismo territorio corresponden a una sola Administración, o en términos más generales, a un sólo ente público, la ordenación del territorio planteará siempre problemas de organización, pero no originará más problemas jurídicos en sentido estricto que aquellos que surjan de la relación entre las potestades de la Administración (o los poderes del ente público) y los derechos de los particulares. Este supuesto se da raras veces, sin embargo, en la realidad. La idea de "ordenación" (o de "planificación", que es el término utilizado en otras lenguas europeas) del territorio nació justamente de la necesidad de coordinar o armonizar, desde el punto de vista de su proyección territorial, los planes de actuación de distintas Administraciones. Cuando la función ordenadora se atribuye a una sola de estas Administraciones, o, como entre nosotros sucede, a entes dotados de autonomía política constitucionalmente garantizada, esa atribución no puede entenderse en términos tan absolutos que elimine o destruya las competencias que la propia Constitución reserva al Estado, aunque el uso que éste haga de ellas condicione necesariamente la ordenación del territorio». Con posterioridad, la STC 149/1998 (BOE, núm. 181, de 30-07-1998), también realiza una aproximación global al concepto y recuerda la doctrina jurisprudencial fijada. 
REALA. Nueva Época - N. ${ }^{0}$ 10, Octubre 2018 - ISSN: 1989-8975 - DOI: 10.24965/reala.v0i10.10518 - [Págs. 109-131]

La anulación del Plan de Protección del Corredor Litoral de Andalucía por el Tribunal Superior de Justicia de Andalucía: ¿nuevas...

Esther Rando Burgos

vuelven y al que necesariamente han de atenerse, el marco general de la política territorial autonómica. De esta forma, los planes territoriales son el medio con el que alcanzar el modelo territorial previsto para el marco autonómico, lo que en el caso de Andalucía, se contiene en el Plan de Ordenación del Territorio de Andalucía, en cuanto instrumento de alcance regional.

En efecto, en su redacción original, la LOTA, distingue dos instrumentos claves para desarrollar la planificación territorial en el ámbito de esta Comunidad Autónoma: el Plan de Ordenación del Territorio de Andalucía, POTA, y los Planes de Ordenación del Territorio de ámbito subregional, POTS.

Significativo sin duda, que una comunidad como Andalucía con $945 \mathrm{~km}$ de costa y la cuarta Comunidad Autónoma con más kilómetros de litoral, tras los dos archipiélagos y Galicia, no incluyera entre sus prioridades la planificación territorial integral de su espacio litoral, máxime cuando desde sus inicios éste ha sido uno de los tres ámbitos prioritarios en que ha centrado sus esfuerzos el planificador territorial andaluz, si bien desde la escala subregional.

No se puede obviar el precedente a lo que es hoy el Plan de Protección del Corredor Litoral de Andalucía (en adelante, PPCLA): las Directrices Regionales del Litoral de Andalucía, formuladas en 1985 y aprobadas en $1990^{10}$, un instrumento que ya durante su tramitación se enfrentó a distintas viscitudes como la aprobación de sucesivos cuerpos normativos con diferente grado de incidencia en la materia que regulaba y que sin duda dificultó que vieran la luz, lo que ya parecía predecir su nula aplicación y eficacia práctica ${ }^{11}$. Como cuestiones más reseñables de aquellas Directrices Regionales podemos destacar su completa descripción del litoral andaluz y las directrices orientadas a la conservación y recuperación de los valores ambientales o la distinción de un total de ocho unidades territoriales (sierras litorales y prelitorales, acantilados, dunas y arenales costeros, ramblas, lagunas litorales, playas, estuarios y marismas, provincia nerítica y plataforma continental).

Como antecedente inmediato del PPCLA, debemos referirnos a su origen político y su eventual concepción como mecanismo de oposición a la reforma de la legislación de costas que en esos momentos se venía tramitando en las Cortes Generales ${ }^{12}$. De esta forma, el acuerdo de gobierno de 18 de abril de 2012 firmado, y publicado, entre las dos formaciones políticas que se coaligaron en el gobierno andaluz ${ }^{13}$, es el germen de lo que más tarde constituiría el denominado PPCLA. Entre los acuerdos adoptados en el marco de "Andalucía diálogo corresponsable, serio y activo con el Gobierno de España desde la defensa del Estatuto de Autonomía para Andalucía", en materia de medio ambiente, ordenación del territorio e infraestructuras, se concierta la «defensa del litoral andaluz frente a la reforma de la Ley de Costas, que permite preservar nuestro litoral, ya castigado por las construcciones y urbanizaciones tales como el Hotel el Algarrobico pendiente de demolición y otras que han degradado y devastado el litoral andaluz»" ${ }^{14}$.

Apenas unos meses después, Andalucía opta definitivamente por incluir un instrumento de planificación territorial centrado en el conjunto litoral de la Comunidad Autónoma ${ }^{15}$. Y ello lo hace a través del Decreto-ley 5/2012, de 27 de noviembre, de medidas urgentes en materia urbanística y para la protección del litoral, con el que se crea ex novo y se incorpora un tercer instrumento a la tipología de planes territoriales: el Plan de

10 Las Directrices Regionales del Litoral de Andalucía fueron formuladas en el año 1985 mediante Decreto 76/1985, de 3 de abril, por el que se autoriza la formulación de las Directrices Regional del Litoral de Andalucía (BOJA, núm. 45, de 10 de mayo de 1985), aunque su aprobación no tuvo lugar hasta el año 1990 con el Decreto 118/1990, de 17 de abril, por el que se aprueban las Directrices Regionales del Litoral de Andalucía, (BOJA, núm. 40, de 18 de mayo de 1990), entrando en vigor el día 19 de mayo de 1990.

11 Durante la tramitación de las Directrices Regionales del Litoral de Andalucía, fueron aprobados diferentes cuerpos normativos con distinto grado de incidencia en la materia que constituía su objeto. En concreto, a nivel estatal, fueron aprobadas la Ley 22/1988, de 28 de julio, de Costas; la Ley 29/1985, de 2 de agosto, de Aguas; la Ley 4/1989, de 27 de marzo, de Conservación de los Espacios Naturales y de la Flora y Fauna Silvestre. Asimismo, a nivel autonómico, tuvo lugar la aprobación de la Ley 8/1988, de 2 de noviembre, de Puertos Deportivos de la Comunidad Autónoma de Andalucía y la Ley 2/1989, de 18 de julio, por la que se aprueba el inventario de espacios naturales protegidos de Andalucía y se establecen medidas adicionales para su protección.

Sobre el particular, vid. BARRAGÁN MUÑOZ, J. M. (1993): "Perspectiva regional de la ordenación, planificación y gestión del espacio litoral. El caso andaluz". Revista de Estudios Regionales, núm. 37, 1993, pág. 131.

12 Dando lugar a que el 5 de octubre de 2012, el Consejo de Ministros aprobase, a propuesta del Ministerio de Agricultura, Alimentación y Medio Ambiente, el Proyecto de Ley de Protección y Uso Sostenible del Litoral y de modificación de la Ley de Costas de 1988. Proyecto de Ley que fue aprobado el 13 de diciembre de 2012 por el Congreso de los Diputados.

${ }_{13}$ Acuerdo por Andalucía, adoptado entre PSOE Andalucía/IULV-CA, el día 18 de abril de 2012. Disponible en http://www.izquierda-unida.es/sites/default/files/doc/Acuerdo\%20por\%20Andaluc\%C3\%ADa.pdf.

14 Ibídem, pág. 64

15 Sobre la ordenación del litoral, vid. NÚÑEZ LOZANO, M. C. (2016): Estudios Jurídicos sobre el litoral, Tirant Lo Blanch y RODRÍGUEZ VIDAL, J. y NÚÑEZ LOZANO, M. C. (2015): Litoral de Andalucía: normas y naturaleza, Universidad de Huelva. 
REALA. Nueva Época - N. 10, Octubre 2018 - ISSN: 1989-8975 - DOI: 10.24965/reala.v0i10.10518 - [Págs. 109-131]

La anulación del Plan de Protección del Corredor Litoral de Andalucía por el Tribunal Superior de Justicia de Andalucía: ¿nuevas...

Esther Rando Burgos

Protección del Corredor del Litoral de Andalucía ${ }^{16}$. El Decreto-ley $5 / 2012^{17}$, modifica para ello la LOTA a la que introduce el Título VII, centrado en la regulación jurídica del nuevo instrumento ${ }^{18}$, previendo aspectos como su objeto, efectos y ámbito (art. 42), el contenido (art. 43) o el procedimiento para la elaboración y aprobación del plan (art. 44). Finalmente, será el Acuerdo del Consejo de Gobierno de 29 de enero de 2013, el que formule el PPCLA, conforme al propio Título VII de la LOTA ${ }^{19}$.

\subsection{Principios y objetivos}

Desde sus inicios, la planificación territorial en Andalucía se ha centrado en tres ámbitos prioritarios: aglomeraciones urbanas, zonas de montaña y ámbitos litorales ${ }^{20}$. En efecto, con anterioridad al PPCLA, la práctica totalidad del litoral andaluz, si bien desde la escala subregional, ya se encontraba dotada de instrumentos de planificación territorial ${ }^{21}$.

El art. 42 de la LOTA es escueto al establecer el objeto del PPCLA, atribuyendo únicamente a este instrumento la función de fijar los objetivos, criterios y determinaciones para la protección, conservación y puesta en valor de las zonas costeras de Andalucía, en el marco de las previsiones contenidas en el POTA para el dominio litoral. Previsión que complementa el propio acuerdo de formulación del PPCLA, que se plantea tres objetivos generales: preservar de la urbanización las zonas con valores ambientales, naturales, paisajísticos, culturales, agrícolas y forestales de los espacios litorales; evitar la consolidación de nuevas barreras urbanas entre los espacios interiores y el sistema costero y favorecer la biodiversidad a través de la continuidad de los espacios del interior con los del litoral; armonizar la regulación del suelo no urbanizable en el ámbito del plan ${ }^{22}$.

Con estos antecedentes, el PPCLA en el documento de Memoria de Ordenación se propone el objetivo general que le atribuye el art. 42 de la LOTA en el marco de lo previsto en el POTA, que establece como criterios generales para la ordenación territorial de los ámbitos litorales, la consideración unitaria de la sostenibilidad económica y ecológica del litoral, la protección integral de los sistemas litorales evitando la formación de continuos urbanos en el frente costero, la preservación del patrimonio natural y paisajístico y la protección de la costa frente a los riesgos de erosión.

Objetivo general que se desarrolla a través de un conjunto de objetivos específicos, que son idénticos a los ya establecidos en el acuerdo de formulación del PPCLA, únicamente con una novedad, al incorporar a aquéllos, el propiciar el mantenimiento del litoral como recurso turístico básico evitando su consolidación con nuevos usos residenciales estacionales.

EI PPCLA parte de la consideración del corredor litoral andaluz como un recurso territorial esencial de Andalucía y en el que han de centrarse los esfuerzos con un propósito de partida: compatibilizar el desarrollo económico con la protección y preservación de la urbanización de los espacios aun libres de edificación en la franja costera. En suma, el PPCLA implícitamente viene a incorporar una de las grandes metas de la Ley del Suelo de 2007 y acogida paulatinamente por diferentes marcos autonómicos, el principio de desarrollo territorial y urbano sostenible cuyo máximo exponente es el doble valor del suelo como recurso económico

16 Vid. los trabajos de ZAMORANO WISNES, J. (2016): "La ordenación del litoral en Andalucía. El Plan de Protección del Corredor Litoral de Andalucía", en NÚÑEZZ LOZANO, M. C. (dir.) Estudios Jurídicos sobre el litoral, Tirant Lo Blanch, págs. 87-130 y ZAMORANO WISNES, J. (2013): "Comentarios al Decreto-Ley 5/2012 de medidas urgentes en materia urbanística y para la protección del litoral de Andalucía", Administración de Andalucía: Revista Andaluza de Administración Pública, núm. 85, págs. 149-186.

17 Posteriormente convalidado por el Parlamento de Andalucía, mediante Resolución de 12 de diciembre de 2012, de la Presidencia, por la que se acuerda la publicación del acuerdo de convalidación del Decreto-ley 5/2012, de 27 de noviembre, de medidas urgentes en materia urbanística y para la protección del litoral de Andalucía (BOJA núm. 253, de 28-12-2012).

${ }^{18}$ Este título fue introducido por el apartado 3. ${ }^{\circ}$ del artículo 1 del Decreto-ley 5/2012, de 27 de noviembre.

19 BOJA núm. 32, de 14-02-2013.

20 RANDO BURGOS, E. (2018a): Áreas de oportunidad y ordenación..., op. cit.

${ }^{21}$ En concreto, los ámbitos coincidentes con los siguientes planes: POTS del Litoral Occidental de Huelva (2006), POTS del Ámbito de Doñana (2004), POTS de la Costa Noroeste de Cádiz (2011), POTS de la Bahía de Cádiz (2004), POTS de la Janda (2011), POTS del Campo de Gibraltar (2012), POTS de la Costa del Sol Occidental de Málaga (2006), POTS de la Aglomeración Urbana de Málaga (2009), POTS del Litoral Oriental Axarquía de Málaga (2006), POTS de la Costa Tropical de Granada (2006), POTS del Poniente de Almería (2002), POTS de la Aglomeración Urbana de Almería (2012): y POTS del Levante Almeriense (2009).

${ }^{22}$ La protección del medio ambiente es una de las metas de la ordenación del territorio. Sobre el particular y la atención prestada por las diferentes Comunidades Autónomas, vid. RANDO BURGOS. E. (2018b): "La atención al medio ambiente desde la ordenación del territorio: una visión general desde el marco legislativo autonómico". Actualidad Jurídica Ambiental, núm. 81, julio 2018, págs. 121-156.

Disponible http://www.actualidadjuridicaambiental.com/comentario-legislativo-la-atencion-al-medio-ambiente-desde-la-ordenacion-delterritorio-una-vision-general-desde-el-marco-legislativo-autonomico/. 
REALA. Nueva Época - N. 10 , Octubre 2018 - ISSN: 1989-8975 - DOI: 10.24965/reala.v0i10.10518 - [Págs. 109-131]

La anulación del Plan de Protección del Corredor Litoral de Andalucía por el Tribunal Superior de Justicia de Andalucía: ¿nuevas...

Esther Rando Burgos

pero a su vez como recurso natural, escaso y no renovable. En este sentido, hay que reconocer al PPCLA su carácter innovador al proponerse como meta conjugar la planificación física del suelo con el desarrollo económico de la comunidad, desarrollando y tratando de instrumentalizar lo que en el momento actual y en la práctica se reduce a una declaración de principios que busca su desarrollo para alcanzar la meta: un desarrollo territorial y urbano sostenible.

\section{3. Ámbito territorial}

Con carácter general, el art. 42.3 de la LOTA indica que el ámbito del PPCLA, incluye los primeros 500 metros de la zona de influencia de litoral, así como aquellas otras zonas necesarias para alcanzar los objetivos de protección y accesibilidad del sistema costero. El precepto, remite a su vez al anexo I de la LOTA que contiene la relación de municipios incluidos en su ámbito, clasificados por provincias, y que integra a la totalidad de municipios litorales andaluces ${ }^{23}$.

\subsection{Naturaleza jurídica y relación con otros instrumentos de planificación territorial}

EI PPCLA es un instrumento al que la LOTA posiciona a caballo entre el POTA y los POTS, pero que sin embargo, se opta por no incluir en ninguna de las dos categorías preexistentes y se dota de entidad propia. Pese a su carácter integral al planificar un ámbito concreto del territorio andaluz con singulares características, el conjunto litoral, y en la medida en que no afecta al conjunto de la Comunidad Autónoma, parece que no procede predicar del PPCLA su carácter de instrumento de planificación regional. En similar sentido, ocurre con los instrumentos de planificación territorial de escala subregional, el ámbito del PPCLA excede al propio de aquéllos, por lo que tampoco hubiera sido adecuado incluirlo en tal categoría ${ }^{24}$.

Por tanto, dada la imposibilidad de incluirlo en ninguna de las categorías preexistentes, y en consonancia con lo que hace la propia LOTA, podemos afirmar que estamos ante un instrumento sui generis, creado para un ámbito particular del territorio andaluz.

Sin embargo, son diversas las referencias del articulado de la ley que directamente remiten la regulación del PPCLA a las previsiones contempladas para los POTS. A modo de ejemplo, cuando el art. 42.2 de la LOTA, regula el sistema de vinculación del PPCLA con los restantes instrumentos de planificación territorial, únicamente señala su carácter vinculante para los POTS pero ninguna mención se hace siquiera al propio POTA, cuestión que se ha de completar con la previsión del art. 22.1 de la LOTA, que posiciona este último en la cúspide del sistema jerárquico que establece, e indica su carácter vinculante para el resto de instru-

${ }^{23}$ En concreto, distingue:

- Provincia de Almería: Adra, Almería, Berja, Carboneras, Cuevas de Almanzora, Ejido (El), Enix, Garrucha, Mojácar, Nijar, Pulpí, Roquetas de Mar, Vera.

- Provincia de Cádiz: Algeciras, Barbate, Barrios (Los), Cádiz, Chiclana de la Frontera, Chipiona, Conil de la Frontera, Línea de la Concepción (La), Puerto de Santa María (El), Puerto Real, Rota, San Fernando, San Roque, Sanlúcar de Barrameda, Tarifa, Vejer de la Frontera.

- Provincia de Granada: Albuñol, Almuñécar, Gualchos, Lújar, Motril, Polopos, Rubite, Salobreña, Sorvilán.

- Provincia de Huelva: Almonte, Ayamonte, Cartaya, Huelva, Isla-Cristina, Lepe, Lucena del Puerto, Moguer, Palos de la Frontera, Punta Umbría.

- Provincia de Málaga: Algarrobo, Benalmádena, Casares, Estepona, Fuengirola, Málaga, Manilva, Marbella, Mijas, Nerja, Rincón de la Victoria, Torremolinos, Torrox, Vélez-Málaga.

${ }^{24}$ En este sentido, el camino elegido por las diferentes Comunidades Autónomas ha sido dispar, así mientras unas han decidido incluir sus planes territoriales para los ámbitos litorales como instrumentos de planificación territorial de ámbito regional, otras han optado abiertamente por hacerlo a través de instrumentos de ámbito subregional, sin crear una categoría específica. Entre estas últimas, se encuentra el Principado de Asturias (Directrices Subregionales de Ordenación del Territorio para la Franja Costera, aprobadas por Decreto 107/1993, de 16 de diciembre) o Galicia (Plan de Ordenación del Litoral de Galicia, aprobado por Decreto 20/2011, de 10 de febrero).

En el caso de Cantabria, sin embargo, se opta por equiparar el instrumento de planificación territorial litoral, el Plan de Ordenación del Litoral de Cantabria, al instrumento de planificación territorial de ámbito regional, el Plan Regional de Ordenación Territorial. Así se establece en la disposición adicional cuarta de la Ley 2/2001, de 25 de junio, de Ordenación Territorial y Régimen Urbanístico del Suelo de Cantabria, que en su apartado 1 dispone «En atención a las peculiaridades y especial singularidad de la zona costera, y con la finalidad de una protección efectiva e integral de la misma, el Gobierno elaborará un Plan de Ordenación del Litoral que queda equiparado a todos los efectos al Plan Regional de Ordenación Territorial previsto en el artículo 11 de esta Ley y que se elaborará de acuerdo con el procedimiento del artículo 16 de la misma. A dicho Plan le será especialmente aplicable lo dispuesto en los artículos 15,17 y 18 de la presente Ley y podrá ser desarrollado, en su caso, en los términos del apartado 1 de su artículo 59». 
REALA. Nueva Época - N. 10 , Octubre 2018 - ISSN: 1989-8975 - DOI: 10.24965/reala.v0i10.10518 - [Págs. 109-131]

La anulación del Plan de Protección del Corredor Litoral de Andalucía por el Tribunal Superior de Justicia de Andalucía: ¿nuevas...

Esther Rando Burgos

mentos de planificación territorial ${ }^{25}$. Tampoco precisa su relación con los planes de incidencia territorial o el planeamiento urbanístico, limitándose el precepto a remitir a la regulación que la misma establece para los POTS, lo que obliga a poner en relación el citado art. $42.2 \mathrm{con}$ el art. 23 de la LOTA para poder establecer el completo marco de jerarquía que despliega el PPCLA.

De la conjunción de los preceptos indicados, ha de interpretarse que el PPCLA queda únicamente vinculado por el POTA, y que a su vez, sus determinaciones resultan vinculantes tanto para los POTS, como para los Planes con Incidencia en la Ordenación del Territorio y para el propio planeamiento urbanístico municipal.

\subsection{La tramitación del PPCLA de conformidad con la LOTA}

Un único precepto dedica la LOTA a regular el procedimiento de tramitación y aprobación del PPCLA, el art. 44. Conforme al cual, se distinguen las siguientes fases:

- EI PPCLA se formulará por acuerdo del Consejo de Gobierno a propuesta de la persona titular de la Consejería competente en materia de ordenación del territorio.

- Redactado el PPCLA se someterá, por un plazo no inferior a dos meses, a información pública y audiencia a las Administraciones y Entidades Públicas afectadas en razón de su competencia así como a las Corporaciones Locales que tengan todo o parte de su territorio incluido en el ámbito del plan.

- El PPCLA será aprobado por Decreto del Consejo de Gobierno, dando cuenta al Parlamento de Andalucía y publicándose en el Boletín Oficial de la Junta de Andalucía para su efectividad.

Sin duda, la primera cuestión que sorprende es la simplicidad que emplea la LOTA al regular el proceso que, para su elaboración y tramitación, ha de seguir el PPCLA. Aún conscientes del carácter escueto que en general caracteriza a la LOTA en su articulado, este rasgo queda enfatizado en este precepto concreto.

Pero junto a lo anterior, no menos sorpresivo resulta la omisión de cuestiones como el contenido del acuerdo de formulación del PPCLA (tanto en la regulación de la tramitación del POTA como de los POTS, a diferencia del PPCLA, se establece expresamente la necesidad de que el acuerdo de formulación incluya los objetivos generales del instrumento, así lo prevé los arts. 8.2 y 13.3 de la LOTA). Como tampoco se establece siquiera, la necesidad de constituir una comisión de redacción, cuya composición y funciones sea establecida por el acuerdo de formulación, o el propio procedimiento y el plazo para su elaboración. Todos estos aspectos, de carácter obligatorio tanto para la elaboración del POTA como de los POTS, bien parece que fueron un olvido del legislador andaluz al incluir y regular la figura del PPCLA. También sorprende que ninguna mención se contenga respecto a la participación en la comisión de redacción de representantes de los municipios afectados por el ámbito del plan.

Todas estas cuestiones tuvieron que ser abordadas por el acuerdo de formulación que vino con ello a completar los aspectos procedimentales a que debía someterse el PPCLA, ante el rotundo silencio de la LOTA. Sin duda, reprochable desde el punto de vista jurídico porque además supone un desigual tratamiento respecto a los restantes instrumentos de planificación territorial previstos en la ley ${ }^{26}$ y contradice el propio art. 1 de la LOTA que establece como objeto de la misma «la regulación de los instrumentos y procedimientos para el ejercicio por la Junta de Andalucía de su competencia en Ordenación del Territorio». En suma, como ya se apuntó líneas atrás, todo ello denotaba demasiada urgencia en su aprobación y la prevalencia de la misma sobre las propias garantías procedimentales del PPCLA.

25 De hecho, parece evidente que ésta es la intención del legislador andaluz, toda vez que el propio Decreto-ley 5/2012, modifica el apto. 1 del art. 22, cuya redacción anterior indicaba la vinculación del POTA para los POTS y para los Planes con Incidencia en la Ordenación del Territorio. Con la modificación, se sustituye el término «planes de ordenación del territorio de ámbito subregional» por «planes territoriales», con lo que quedan vinculados por el POTA ambos instrumentos e incluso, cualesquiera otros que con posterioridad pudiera incorporar la ley.

${ }^{26} \mathrm{El}$ art.8.1. de la LOTA, en relación con el POTA, dispone «El acuerdo de formulación establecerá los objetivos generales que habrán de orientar su redacción, la composición y funciones de la Comisión de Redacción y el procedimiento y plazo para su elaboración». De similar manera y en referencia a los POTS, el art. 13 de la LOTA, en sus aptdos. 1 y 3, establece «Corresponde al Consejo de Gobierno acordar la formulación de los Planes de Ordenación del Territorio de ámbito subregional, a propuesta del Consejero de Obras Públicas y Transportes de oficio o a instancia de las Corporaciones Locales» y "El acuerdo establecerá el ámbito, los objetivos generales que habrán de orientar su redacción, la composición y funciones de la Comisión de Redacción y el procedimiento y plazo para su elaboración», respectivamente. Contrariamente, al art. 44.1. de la LOTA, que al regular el procedimiento del PPCLA, la única referencia al acuerdo de formulación la señala en su aptdo. 1, así dispone «El Plan de Protección del Corredor Litoral de Andalucía se formulará por Acuerdo del Consejo de Gobierno a propuesta de la persona titular de la Consejería competente en materia de ordenación del territorio». 
REALA. Nueva Época - N. 10, Octubre 2018 - ISSN: 1989-8975 - DOI: 10.24965/reala.v0i10.10518 - [Págs. 109-131]

La anulación del Plan de Protección del Corredor Litoral de Andalucía por el Tribunal Superior de Justicia de Andalucía: ¿nuevas...

Esther Rando Burgos

\subsection{El proceso de tramitación del PPCLA}

Si sorpresivo resultó el Decreto-ley 5/2012, de 27 de noviembre, de medidas urgentes en materia urbanística y para la protección del litoral, no menos lo fue el tiempo, insólitamente breve, en que se proponía inicialmente, tramitar y aprobar el PPCLA: dos años. La experiencia acumulada por Andalucía en ese momento tenía buenas razones para ello. Más de una década fue necesaria desde que se acordó la formulación del POTA (Decreto 83/1995, de 28 de marzo) hasta que definitivamente fue aprobado (Decreto 206/2006, de 28 de noviembre), e incluso en el ámbito de planificación territorial subregional, había sido necesario el transcurso de plazos muy superiores a aquél para la aprobación de no pocos instrumentos. Ejemplos no faltaban: POTS del Poniente de Almería, seis años ${ }^{27}$, POTS Sierra de Segura, siete años ${ }^{28}$, idéntico plazo al que preciso el POTS del Litoral Occidental de Huelva ${ }^{29}$, incluso en los últimos planes aprobados (POTS de la Costa Noroeste de Cádiz ${ }^{30}$, POTS de La Janda ${ }^{31}$, POTS de la aglomeración urbana de Almería ${ }^{32}$, POTS del Campo de Gibraltar ${ }^{33}$, POTS de la Costa Tropical de Granada ${ }^{34}$, POTS del Sur de Córdoba ${ }^{35}$ y POTS de la aglomeración urbana de Jaén ${ }^{36}$ ). Los precedentes existentes en Andalucía, evidenciaban que el tiempo requerido para la elaboración y aprobación de los planes territoriales, resultaba, por lo general, muy superior al plazo de dos años previsto, oscilando en torno a cuatro años. Sin duda, todo un reto desde su inicio.

Los principales hitos que tuvieron lugar durante la tramitación del PPCLA, desde la aprobación del citado Decreto-ley 5/2012, de 27 de noviembre, de medidas urgentes en materia urbanística y para la protección del litoral hasta su definitiva aprobación en 2015 , son los que a continuación se enumeran:

\subsubsection{Decreto-ley 5/2012, de $\mathbf{2 7}$ de noviembre, de medidas urgentes en materia urbanística y para la protección del litoral}

La sorpresiva publicación del Decreto-ley 5/2012, no estuvo exenta de polémicas. La aprobación vía decreto ley por el gobierno andaluz o la justificación que contiene en su propia exposición de motivos a las razones que motivan su "extraordinaria y urgente necesidad ${ }^{37}$, incluso el momento político en que se produce $^{38}$, no pasaron, como decimos, inadvertidos, abriendo un extenso debate ${ }^{39}$.

27 Formulado por Decreto 6/1996, de 9 de enero y aprobado definitivamente por Decreto 222/2002, de 30 de julio.

28 Formulado por Decreto 5/1996, de 9 de enero y aprobado definitivamente por Decreto 219/2003, de 22 de julio.

29 Formulado por Decreto 52/1999, de 2 de marzo y aprobado definitivamente por Decreto 130/2006, de 27 de junio.

30 Formulado por Decreto 97/2007, de 27 de marzo y aprobado definitivamente por Decreto 95/2011, de 19 de abril.

31 Formulado por Decreto 90/2007, de 27 de marzo y aprobado definitivamente por Decreto 358/2011, de 8 de noviembre.

32 Formulado por Decreto 521/2008, de 9 de diciembre y aprobado definitivamente por Decreto 351/2011, de 29 de noviembre.

33 Formulado por Decreto 88/2007, de 27 de marzo y aprobado definitivamente por Decreto 370/2011, de 20 de diciembre.

34 Formulado por Decreto 59/2006, de 14 de marzo y aprobado definitivamente por Decreto 369/2011, de 20 de diciembre.

35 Formulado por Decreto 34/2009, de 17 de febrero y aprobado definitivamente por Decreto 3/2012, de 10 de enero.

36 Formulado por Decreto 243/2011, de 12 de julio y aprobado definitivamente por Decreto 142/2004, de 14 de octubre.

37 Cuestión sobre la que la exposición de motivos señala expresamente «El presente Decreto-Ley viene pues a establecer un conjunto de medidas legislativas muy concretas en el ámbito de la ordenación del territorio y el urbanismo cuyo objeto es posibilitar la intervención inmediata en la protección del ámbito litoral e incentivar el cumplimiento de las determinaciones del Plan de Ordenación del Territorio de Andalucía. Además, se incluyen medidas para agilizar la tramitación del planeamiento urbanístico y conseguir de una manera efectiva e inmediata los fines antes reseñados. Medidas legislativas cuya extraordinaria y urgente necesidad encuentran plena justificación en el contexto de la grave crisis económica en la que nos encontramos, ya que la agilización perseguida favorecerá el desarrollo de las actividades económicas y coadyuvará a salvaguardar de la forma más inmediata posible la calidad ambiental y paisajística del litoral, que sustenta una parte muy importante de la competitividad de sus destinos turísticos. Con ello se evitan situaciones irreversibles tanto en la protección de nuestro litoral como en el conjunto de la región que pongan en peligro la sostenibilidad de nuestro sistema territorial y urbano. En particular, la tramitación como Decreto Ley se justifica por la necesidad de suspender de forma inmediata y urgente durante la elaboración del Plan de Protección del Corredor Litoral de Andalucía la tramitación de los planes de sectorización y de los planes parciales en suelo urbanizable ubicados en el ámbito del Plan». Lo que para LA CALLE, A. supone una cierta contradicción, al entender que «... resulta difícil de imaginar cómo pueden coadyuvar a la salvaguarda de la calidad ambiental y paisajística del litoral el desarrollo de actividades económicas de ocupación del suelo...», y abundando en dicha idea, destaca que "... se trata de problemas ya conocidos desde hace tiempo cuya urgencia deriva más de los ritmos de la agenda política que de la realidad social, económica y ambiental...».

En LA CALLE, A. (2013): "Derecho y políticas ambientales en Andalucía", Revista Catalana de Dret Ambiental, vol. IV, núm. 1, págs. 2 y 3 .

38 Para autores como MARTíN VALDIVIA, S. M., las medidas adoptadas para la protección del litoral andaluz responden más al oportunismo político que a la oportunidad real y jurídica.

En MARTÍN VALDIVIA, S. M. (2013): "La protección del litoral andaluz y otras medidas de urgencia: entre la necesidad y el oportunismo", Revista de Urbanismo y Edificación, núm. 27, págs. 51-89.

39 Entre los debates surgidos, también destaca la crítica a la falta de sostenibilidad económica del PPCLA conforme al concepto introducido por la Ley 8/2007, de 28 de mayo, de Suelo e incorporado en el art. 15.4. del Real Decreto Legislativo 2/2008, de 20 de 
REALA. Nueva Época - N. ${ }^{10}$, Octubre 2018 - ISSN: 1989-8975 - DOI: 10.24965/reala.v0i10.10518 - [Págs. 109-131]

La anulación del Plan de Protección del Corredor Litoral de Andalucía por el Tribunal Superior de Justicia de Andalucía: ¿nuevas...

Esther Rando Burgos

La principal finalidad del Decreto-ley $5 / 2012^{40}$ es crear la figura del PPCLA y consecuente con ello, organizar el marco jurídico para posibilitar su definitiva puesta en marcha. Por ello, se propone unos claros objetivos desde su inicio: modificar la LOTA para incluir el nuevo instrumento de planificación territorial (no debe olvidarse que es un instrumento creado ex novo y no previsto hasta ese momento en el modelo de planificación territorial diseñado por Andalucía que se había centrado en dos ámbitos muy precisos: el regional, configurado a través del POTA, y el subregional, a través de los POTS). Pero junto a aquél, el Decreto-ley $5 / 2012$, adopta medidas cautelares urgentes en el ámbito litoral que se extienden desde su entrada en vigor y hasta la aprobación del PPCLA para determinados municipios costeros, y medidas urgentes para la adecuación del planeamiento urbanístico al POTA.

En relación con la modificación de la LOTA, cuestión que aborda en su art. 1, se incorporan cuestiones de interés: la propia inclusión del PPCLA como nueva categoría en la clasificación de instrumentos de planificación territorial, modificando el art. 5 de la LOTA, su propia ubicación entre el POTA y los POTS, ya adelanta la intención de dotarlo de entidad propia y del carácter de este instrumento, a caballo entre el POTA y los POTS. Bien podía haberse optado por clasificarlo directamente como POTS en la medida en que abarca un ámbito inferior al regional, sin embargo, sus concretas características y la particularidad del ámbito que está llamado a planificar parecen justificar esta necesidad de crear un categoría creada ex novo. Consecuente con este carácter al que nos referimos es la necesaria modificación del art. 22.1 de la LOTA, al que se hacía referencia con anterioridad, y que determina la supremacía del POTA así como su carácter vinculante para el «resto de planes territoriales», incluyéndose en estos tanto los POTS pero también el PPCLA, así como los Planes con Incidencia en la Ordenación del Territorio y el planeamiento urbanístico general.

Junto a las anteriores, la principal modificación que tiene lugar es la incorporación de un nuevo título, numerado como VII, conformado por tres artículos (42, 43 y 44) y que se instituye como el marco jurídico que regula la nueva figura. Siguiendo la propia tendencia de la LOTA como cuerpo legal generalista y simplista en sus determinaciones, la regulación del PPCLA se centra en determinar su objeto (establecer objetivos, criterios y determinaciones para la protección, conservación y puesta en valor de las zonas costeras de Andalucía, en el marco de lo establecido en el POTA para el dominio litoral), efectos (vinculación del PPCLA para los POTS, teniendo los demás efectos establecidos para estos planes) y ámbito (con carácter general, al menos los primeros $500 \mathrm{~m}$ de la zona de influencia del litoral, pero además, se posibilita extender su ámbitos a otras zonas necesarias para alcanzar los objetivos de protección y accesibilidad del sistema costero de los propios municipios litorales andaluces). Todas estas cuestiones son objeto de regulación en el art. 42 de la LOTA.

Por su parte, el nuevo art. 43 de la LOTA se centra en el contenido que habrá de tener el PPCLA, distinguiendo:

- Los objetivos territoriales a alcanzar y las propuestas a desarrollar durante la vigencia del plan.

- La delimitación concreta del ámbito territorial del plan y de la zona de influencia del litoral.

- La indicación de zonas que por motivos territoriales o de protección deben ser preservadas del desarrollo urbanístico.

- Las determinaciones precisas para garantizar un régimen homogéneo para las diferentes categorías de suelo no urbanizable de todo el ámbito del plan.

- El establecimiento de corredores o ámbitos de conexión del sistema costero con el interior territorial.

- Las determinaciones de los Planes de Ordenación del Territorio de ámbito subregional, de los Planes con Incidencia en la Ordenación del Territorio y del planeamiento urbanístico que deban ser objeto de adaptación, justificando las alteraciones propuestas para los mismos.

- Las previsiones para el desarrollo, seguimiento y ejecución del plan.

Por último, el art. 44 está dedicado a regular el procedimiento que, para su elaboración y aprobación, habría de seguir el PPCLA.

junio, por el que se aprueba el texto refundido de la Ley del Suelo. Para autores como SERRANO LÓPEZ y SERRANO MORENO, la memoria económica del PPCLA representa un claro intento de "escapar» a la obligación de justificar sus implicaciones económicas, obligación que deviene además del propio art. 12.c) de la LOTA. Para estos autores también queda en entredicho el respeto a los principios de seguridad jurídica y de protección de la confianza inherente en un Estado de Derecho de las medidas de protección del litoral adoptadas por el Decreto-ley 5/2012.

En SERRANO LÓPEZ, J. E. y SERRANO MORENO, J. E. (2016): "La (in)sostenibilidad económica y financiera del plan de protección del corredor litoral de Andalucía", Revista de Derecho Urbanístico y Medio Ambiente, núm. 306, Madrid, junio (2016), págs. 69-103.

40 BOJA núm. 233, de 28-11-2012. 
REALA. Nueva Época - N. ${ }^{10}$ 10, Octubre 2018 - ISSN: 1989-8975 - DOI: 10.24965/reala.v0i10.10518 - [Págs. 109-131]

La anulación del Plan de Protección del Corredor Litoral de Andalucía por el Tribunal Superior de Justicia de Andalucía: ¿nuevas...

Esther Rando Burgos

Por su parte, el Decreto-ley 5/2012, incorpora un nuevo anexo a la LOTA, el hasta entonces anexo único pasa a renumerarse como anexo II, en el que se relacionan los municipios costeros de Andalucía a efectos de las determinaciones del plan, concordante con lo dispuesto en el propio art. 42.3 que incorpora a la LOTA.

La segunda cuestión que aborda el Decreto-ley 5/2012 es la adopción de medidas cautelares urgentes en el ámbito litoral, a lo que dedica su art. 2. Para ello, dispone que, desde su entrada en vigor (hecho que tuvo lugar el día 28 de noviembre de 2012, sólo un día después de su aprobación, en que fue publicado en el BOJA, conforme a su disposición final décima) y hasta la aprobación del PPCLA, queda suspendido en un amplio número de municipios costeros cuyo planeamiento general fue aprobado con anterioridad a la entrada en vigor del POTA, el procedimiento para la aprobación de los planes de sectorización y de los planes parciales en suelo urbanizable en aquellos ámbitos que incluyan terrenos situados a una distancia inferior a 500 metros medidos en proyección horizontal tierra adentro, desde el límite interior de la ribera del mar. No obstante, ello es matizado en el propio aptdo. 2 del art. 2 al disponer que desde el inicio de la información pública del PPCLA, la referida suspensión, sólo sería de aplicación a los sectores afectados por las determinaciones del PPCLA identificados expresamente en el documento que en su momento se sometiera a dicho trámite. Para esta limitación se establece inicialmente un plazo temporal de vigencia máxima de dos años ${ }^{41}$ a contar desde la entrada en vigor del Decreto-ley 5/2012 (extensiva por tanto, hasta el 28 de noviembre de 2014), con dos salvedades: si en el referido plazo el correspondiente Plan General de Ordenación Urbanística, PGOU, era adoptado a las determinaciones del POTA, las medidas de suspensión quedaban sin efecto y en todo caso, quedaba extinguida con la entrada en vigor del PPCLA. Esta última previsión parecía dispuesta para el caso en que, finalmente, el PPCLA resultase aprobado antes del plazo de dos años que se preveía.

Pero además, con carácter general en su art. 3 se establecen medidas urgentes de adecuación del planeamiento urbanístico al POTA. La tónica general de no adaptación de los planeamientos urbanísticos generales al POTA y el consecuente incumplimiento de la previsión contenida en el mismo, lleva al Decreto-ley $5 / 2012$ a regular lo que denomina medidas urgentes y cuyo objeto es lograr dicha adaptación. En este sentido, establece que los municipios que a la entrada a su entrada en vigor no hubiesen adaptado su planeamiento general a las determinaciones del POTA y a los criterios para su desarrollo, deben hacerlo mediante su revisión en el plazo establecido en el propio instrumento de planeamiento general a la entrada en vigor del propio Decreto-ley 5/2012 y para el caso de que no lo estableciera, en el plazo máximo de ocho años desde su aprobación definitiva por la Consejería competente en materia de urbanismo. Además establece la consecuencia al incumplimiento del referido deber: la prohibición de tramitar instrumentos de planeamiento de desarrollo que supongan para el municipio un crecimiento superior a los límites establecidos en la norma 45 del POTA y en los criterios para su desarrollo.

\subsubsection{Formulación}

Mediante el Acuerdo del Consejo de Gobierno de 29 de enero de 2013 se formula el PPCLA ${ }^{42}$.

A efectos de su tramitación, el apartado sexto del citado acuerdo, rubricado «elaboración y tramitación», indicaba un plazo máximo de seis meses desde la aprobación del acuerdo para el sometimiento a información pública de su propuesta, por lo que dicho plazo se extendía hasta el 29 de julio de 2013. Además, dispone que, de manera simultánea a aquélla, debía conferirse audiencia a la Administración General del Estado, las Diputaciones Provinciales de Almería, Cádiz, Huelva, Granada y Málaga, los Ayuntamientos de los municipios comprendidos en el ámbito del plan y las restantes Administraciones y Entidades Públicas afectadas en razón de su competencia.

De igual manera, durante el período de información pública, la propuesta del plan habría de someterse a informe de la Comisión de Ordenación del Territorio y Urbanismo de Andalucía y de las Comisiones Provinciales de Ordenación del Territorio y Urbanismo de Almería, Cádiz, Huelva, Granada y Málaga.

Concluido el período de información pública tendría lugar la redacción de la Memoria Ambiental prevista en el artículo 39.4 de la Ley 7/2007, de 9 de julio, de Gestión Integrada de la Calidad Ambiental ${ }^{43}$ incorporándose las consideraciones finales de la misma a la propuesta de PPCLA, que finalmente, sería elevada

41 Con posterioridad ampliado a dos años y seis meses.

42 BOJA, núm. 32, de 14-02-2013.

43 BOJA, núm. 143, de 20-07-2007. 
REALA. Nueva Época - N. ${ }^{10}$ 10, Octubre 2018 - ISSN: 1989-8975 - DOI: 10.24965/reala.v0i10.10518 - [Págs. 109-131]

La anulación del Plan de Protección del Corredor Litoral de Andalucía por el Tribunal Superior de Justicia de Andalucía: ¿nuevas...

Esther Rando Burgos

su propuesta por la persona titular de la Consejería de Agricultura, Pesca y Medio Ambiente al Consejo de Gobierno para su aprobación mediante Decreto, dándose cuenta al Parlamento.

De interés, la previsión contenida en el acuerdo de formulación del PPCLA para la creación de una comisión de redacción del instrumento, a cuyo fin en su apartado quinto, el acuerdo de formulación regula la «composición, funcionamiento y funciones». Adscrita a la Consejería de Agricultura, Pesca y Medio Ambiente y presidida por la persona titular de la Secretaría General de Ordenación del Territorio, la comisión se integra por:

- La persona titular de la Dirección General de Urbanismo que desempeñará la vicepresidencia, sustituyendo a la persona titular de la presidencia en los supuestos de vacante, ausencia o enfermedad de la misma, u otra causa legal.

- Las personas titulares de las Direcciones Generales de Gestión del Medio Natural, de Espacios Naturales y Participación Ciudadana, de Prevención, Calidad Ambiental y Cambio Climático, y de Planificación y de Gestión del Dominio Público Hidráulico de la Consejería de Agricultura, Pesca y Medio Ambiente.

- Una en representación de cada una de las siguientes Consejerías: Hacienda y Administración Pública; Economía, Innovación, Ciencia y Empleo; Fomento y Vivienda; Salud y Bienestar Social; Turismo y Comercio; y Cultura y Deporte, designadas, en cada caso, por la persona titular de la Consejería que corresponda. Dichas personas deberán ostentar, al menos, el rango de Director o Directora General en la Consejería correspondiente.

- Una en representación de la Administración General del Estado.

- Cinco en representación de los ayuntamientos de los municipios incluidos en el ámbito territorial del plan, designadas por la asociación de municipios y provincias con mayor representatividad en la Comunidad Autónoma de Andalucía.

De igual manera, se le atribuyen tres concretas funciones: informar cuantos documentos se sometan a su consideración durante el procedimiento de redacción del plan, informar la propuesta del plan una vez concluida su elaboración técnica, antes de iniciar su tramitación e informar las modificaciones que se introduzcan en la propuesta del plan como consecuencia de los trámites de información pública y de audiencia.

\subsubsection{Información pública}

En relación con la información pública, y conforme a lo dispuesto en el propio acuerdo de formulación que lo fijaba "por un plazo no inferior a dos meses», es mediante la Orden de 24 de julio de 2013 por la que se acuerda someter el PPCLA al referido trámite ${ }^{44}$.

De esta forma, se somete a información pública, tanto el PPCLA como el Informe de Sostenibilidad Ambiental del mismo, desde el día siguiente a su publicación (30 de julio de 2013) y hasta el 31 de octubre del mismo año, período durante el que el instrumento estuvo disponible en la página web de la Consejería ${ }^{45}$.

\subsubsection{Decreto-ley 15/2014, de 25 de noviembre, por el que se modifica el Decreto-ley 5/2012, de 27 de noviembre, de medidas urgentes en materia urbanística y para la protección del litoral de Andalucía}

Justificado por el elevado número de municipios afectados por el PPCLA, un total de 62 , y la activa participación recibida durante el período de información pública, cifrado en un total de 918 escritos con un total de 3.547 alegaciones, mediante el Decreto-ley 15/2014, de 25 de noviembre ${ }^{46}$, se modifica el Decreto-ley $5 / 2012$, de 27 de noviembre, de medidas urgentes en materia urbanística y para la protección del litoral de Andalucía en dos aspectos: el art. 2.3. relativo a la vigencia de las medidas de suspensión acordadas, que se amplía hasta los dos años y seis meses frente a los dos años iniciales, y la disposición adicional única, que en consonancia con lo anterior, amplía en seis meses el plazo fijado para la aprobación del PPCLA, quedando fijado en idéntico plazo de dos años y seis meses a contar desde la entrada en vigor del Decretoley 5/2012, extendiéndose hasta el día 28 de mayo de 2015.

44 BOJA, núm. 147, de 29-07-2013.

45 http://Www.juntadeandalucia.es/agriculturapescaymedioambiente/planlitoral.

46 BOJA, núm. 232, de 27-11-2014. 
Sin duda, esta modificación parece tener su sentido en la experiencia ya acumulada por la Comunidad Autónoma de Andalucía que ya se había enfrentado a sendos recursos judiciales planteados precisamente por la caducidad en los procedimientos de aprobación de otros instrumentos de planificación territorial, como fue el caso del Plan de Ordenación del Territorio del Litoral Occidental de Huelva, y que pese a un primer pronunciamiento en contra y ser posteriormente estimados por el Tribunal Supremo, parecían buscar la máxima cautela en la tramitación del plan a fin de evitar el resultado del que finalmente ha adolecido: su nulidad por defectos formales en su tramitación.

\subsubsection{Aprobación y entrada en vigor}

El día 20 de julio de 2015, era publicado el Decreto 141/2015, de 26 de mayo ${ }^{47}$, por el que se aprueba el Plan de Protección del Corredor Litoral de Andalucía.

Finalmente, y de conformidad con la previsión contenida en la propia disposición final segunda del Decreto 141/2015, el instrumento entraba en vigor el día 21 de julio de 2015.

\subsection{Impugnación del Decreto-ley 5/2012 ante el Tribunal Constitucional y Sentencia del Tribunal Constitucional 27/2016, de 19 de febrero}

La intensidad del debate surgido, fundamentalmente con los municipios, llevó a que las Diputaciones Provinciales de Almería, Granada, Málaga y Cádiz interpusieran un conflicto en defensa de la autonomía local frente al Decreto-ley $5 / 2012^{48}$. El conflicto se sustenta en relación con los arts. 2 y 3 del Decreto-ley 5/2012, de 27 de noviembre, del Consejo de Gobierno de la Junta de Andalucía, de medidas urgentes en materia urbanística y para la protección del litoral de Andalucía ${ }^{49}$, así como respecto de la totalidad del mismo por no concurrir, al entender de los demandantes, la extraordinaria y urgente necesidad que exigen los arts. 86.1 CE y 110 del Estatuto de Autonomía de Andalucía ${ }^{50}$, con lesión de la autonomía local constitucionalmente garantizada.

Conflicto que es inadmitido por la Sentencia del Tribunal Constitucional 27/2016, de 18 de febrero ${ }^{51}$ que, en síntesis, falla la falta de legitimación de las Diputaciones Provinciales que lo promueven, sin entrar al fondo del debate. En la Sentencia, el TC resuelve con carácter previo las causas de inadmisión planteadas por el Parlamento y la Junta de Andalucía, entre otras, la relativa a la falta de legitimación de las promotoras del conflicto. En palabras del TC, en el fundamento jurídico 4 de la Sentencia, la legitimación de la provincia para entablar el conflicto en defensa de la autonomía local, como destinataria única o conjunta de la norma impugnada, exige que la disposición discutida tenga una incidencia directa en su propio ámbito de atribuciones, lo que entiende que no concurre y rechaza que una Diputación provincial pueda impugnar a través de un conflicto en defensa de la autonomía local, una norma con rango de ley para denunciar la vulneración de intereses o competencias exclusivamente municipales. A mayor abundamiento, señala que la disociación de los requisitos formales de legitimación del art. 75 ter. 1 de la Ley Orgánica 2/1979, de 3 de octubre, del Tribunal Constitucional ${ }^{52}$, LOTC, sobre la existencia de una previa afectación del propio ámbito de autonomía de los entes impugnantes llevaría, no sólo a admitir que las Diputaciones pudieran reclamar, en nombre de los municipios de su territorio, la titularidad de una determinada competencia municipal, sino también a aceptar la posibilidad inversa, esto es, que los municipios pudieran entablar, vía art. 75 ter.1, letra b), el conflicto en

47 BOJA, núm. 139.

48 Conflicto en defensa de la autonomía local, núm. 2599-2013. BOE, núm. 226, de 20-09-2013.

49 Art. 2 dedicado a la «adopción de medidas cautelares urgentes en el ámbito del litoral» y art. 3 «medidas urgentes de adecuación del planeamiento urbanístico al Plan de Ordenación del Territorio de Andalucía».

50 Ambos preceptos limitan las disposiciones legislativas provisionales (Decretos-leyes) dictadas por el Gobierno o el Consejo de Gobierno (en el caso de la Comunidad Autónoma) a supuestos de extraordinaria y urgente necesidad. Éste constituye, sin duda, uno de los principales reproches que desde su origen recibe el Decreto-ley 5/2012.

51 BOE, núm. 71, de 23-03-2016.

52 Precepto que dispone que están legitimados para plantear conflictos en defensa de la autonomía local:

- El municipio o provincia que sea destinatario único de la ley.

- Un número de municipios que supongan al menos un séptimo de los existentes en el ámbito territorial de aplicación de la disposición con rango de ley, y representen como mínimo un sexto de la población oficial del ámbito territorial correspondiente.

- Un número de provincias que supongan al menos la mitad de las existentes en el ámbito territorial de aplicación de la disposición con rango de ley, y representen como mínimo la mitad de la población oficial. 
REALA. Nueva Época - N. ${ }^{10}$ 10, Octubre 2018 - ISSN: 1989-8975 - DOI: 10.24965/reala.v0i10.10518 - [Págs. 109-131]

La anulación del Plan de Protección del Corredor Litoral de Andalucía por el Tribunal Superior de Justicia de Andalucía: ¿nuevas...

Esther Rando Burgos

defensa de la autonomía local para denunciar la vulneración de una competencia propia de una Diputación. Y finaliza, señalando que «En suma, ni la naturaleza estrictamente competencial del proceso ni la correcta regulación del mismo permiten sostener que una diputación provincial pueda acudir al conflicto en defensa de la autonomía local para defender competencias estrictamente municipales...».

Con dichas premisas de partida, en el fundamento jurídico 5 , la Sentencia, aplicando los criterios expuestos, señala por un lado, que el conflicto sometido a su enjuiciamiento ha sido entablado por varias Diputaciones provinciales pero además, que invocan como motivo de inconstitucionalidad la vulneración de competencias exclusivamente municipales, lo que le lleva a idéntica conclusión: los entes impugnantes no están legitimados para promover el conflicto planteado.

\section{SENTENCIA DEL TRIBUNAL SUPERIOR DE JUSTICIA DE ANDALUCÍA, SALA DE LO CONTENCIOSO-ADMINISTRATIVO, DE 7 DE SEPTIEMBRE DE 2017, POR LA QUE SE DECLARA LA NULIDAD DEL PLAN DE PROTECCIÓN DEL CORREDOR LITORAL DE ANDALUCÍA}

\subsection{Cuestiones previas}

Adecuado parece, antes de entrar a analizar la referida resolución judicial, hacer un conjunto de reflexiones en torno al momento temporal que en el propio desarrollo de la planificación territorial en Andalucía, se produce. El problema que con la Sentencia se vuelve a evidenciar es de entidad mayor a lo que allí se plantea, y desde luego no es desconocido para la planificación territorial en Andalucía, remontándose a sus propios orígenes.

La cuestión estriba en el propio orden temporal de aprobación de los instrumentos que no ha seguido el esquema previsto por la propia LOTA. Pese al aparente silencio de la LOTA, a nadie escapa que, conforme al propio sistema que establece y las propias vinculaciones que define entre los diferentes instrumentos de planificación territorial, su desarrollo en Andalucía debió dotarse desde el primer momento de un instrumento de ámbito regional en el que se definiera y precisara el modelo territorial para el conjunto autonómico así como las funciones, en su labor de desarrollo, atribuidas a los restantes instrumentos para su consecución.

Cuando en el año 2006, por fin es aprobado el POTA, un buen número de instrumentos de escala subregional (casi la mitad, un total de ocho) ya venían desplegando su eficacia en la comunidad y, todo ello, sin instrumento que desde la escala regional le dotará de cobertura. Un orden lógico adecuado hubiera precisado, seguir en el proceso de tramitación y aprobación, el propio esquema establecido por la LOTA, esto es, en primer lugar la aprobación del POTA, en segundo lugar, el PPCLA y por último, los diferentes POTS.

Sin embargo, se obvió y se continúa haciendo en la actualidad, lo cual resulta contradictorio con el propio sistema de jerarquía definido en la planificación territorial andaluza. Bien parece que en el desarrollo de su política territorial, Andalucía ha actuado a golpe de impulsos políticos. A la postre, ni siquiera con posterioridad, se ha tratado de solventar, revisando los POTS aprobados con anterioridad al POTA a fin de coordinar y adecuar los diferentes instrumentos, e incluso éste último, cuando se decide en el año 2012, incorporar una nueva tipología a las categorías de planes previstas y ya parcialmente desarrolladas en ese momento. No debe olvidarse que ninguna mención contiene el POTA respecto al PPCLA sino que al contrario cuando trata los ámbitos litorales, esenciales para el planificador andaluz, lo hace centrado en su desarrollo a través de los POTS pero no desde la perspectiva integral que se propone el PPCLA. Por ello, parece hubiera resultado adecuado que incluso con anterioridad a la formulación del PPCLA, el POTA hubiese sido objeto de revisión.

Por otra parte, la sorpresiva publicación del Decreto-ley 5/2012 que vino a modificar la LOTA, incorporando un nuevo instrumento de planificación territorial: el PPCLA, es otro de los temas que genera, desde su inicio, incertidumbre. No por el instrumento en sí, sino por el contexto y momento en que se produce. En aquel momento, año 2012, todo hacía indicar que la planificación territorial en Andalucía se encontraba casi concluida. La aprobación de la LOTA en el año 1994, el POTA en 2006 y un total de 17 instrumentos de escala subregional vigentes y que daban cobertura a los ámbitos definidos como prioritarios en la comunidad: aglomeraciones urbanas, ámbitos litorales y zonas de montaña, evidenciaban lo anterior. Ya desde su inicio, lleva al planteamiento de sí realmente lo que estaba teniendo lugar no era un replanteamiento de la propia planificación territorial en la comunidad, pero no en su modelo sino en su conjunto. 
REALA. Nueva Época - N. 10 , Octubre 2018 - ISSN: 1989-8975 - DOI: 10.24965/reala.v0i10.10518 - [Págs. 109-131]

La anulación del Plan de Protección del Corredor Litoral de Andalucía por el Tribunal Superior de Justicia de Andalucía: ¿nuevas...

Esther Rando Burgos

\subsection{Resumen de la Sentencia}

Con fecha 7 de septiembre de 2017, ha sido dictada por el Tribunal Superior de Justicia de Andalucía, Sala de lo Contencioso-administrativo, Sede Sevilla, Sentencia recaída en el recurso núm. 721/2015, de la que ha sido ponente el IImo. Sr. D. José Santos Gómez ${ }^{53}$, por la que se estima el recurso planteado por la Junta de Compensación del sector SL-1 «Valdevaqueros» del Plan General de Ordenación Urbanística de Tarifa frente al Decreto 141/2015, de 26 de mayo, del Consejo de Gobierno de la Junta de Andalucía, por el que se aprueba el Plan de Protección del Corredor Litoral de Andalucía, publicado en el BOJA, núm. 139, de 20 de julio de 2015.

Con idéntico objeto se plantearon otros recursos que han dado lugar, con idéntica fecha y con posterioridad, a diferentes resoluciones judiciales en las que la Sala llega a la misma conclusión: la nulidad de pleno derecho del PPCLA ${ }^{54}$.

Oportuno es, en primer lugar, y sin perjuicio de la doctrina que pueda establecer el posible recurso de casación ${ }^{55}$, destacar que el motivo que determina la nulidad del PPCLA se debe a cuestiones formales ${ }^{56} \mathrm{y}$ en consecuencia, la Sentencia no entra en el análisis de las cuestiones de fondo planteadas por la demandante ${ }^{57}$.

De interés, otros recursos planteados frente a Decreto 141/2015, en particular el rec. núm. 685/2015 resuelto por la STSJ de Andalucía de 11 de octubre de 2017, en que la actora plantea la falta de competencia del Consejo de Gobierno para aprobar el PPCLA por hallarse en funciones. La Sala, al amparo de lo dispuesto en el art. 33 de la Ley 29/1998, de 13 de julio, de la Jurisdicción Contencioso-administrativa, LJCA, somete mediante providencia la cuestión a las partes a fin de conferirles plazo para formular alegaciones.

La Sentencia de 7 de septiembre de 2017 del Tribunal Superior de Justicia de Andalucía, estima el recurso planteado sustentado en un único motivo formal: la falta de competencia del Consejo de Gobierno de la Junta de Andalucía para aprobar el PPCLA, por hallarse en funciones. Sostiene la meritada Sentencia en su F. D. Cuarto un hecho vital en torno al cual gira la resolución judicial y que determina el fallo de la misma: el Consejo de Gobierno de la Junta de Andalucía se encontraba en funciones el día 26 de mayo de 2015 , fecha en que fue aprobado el PPCLA.

53 ECLI: ES:TSJAND:2017:7921.

${ }^{54}$ Entre las Sentencias dictadas por la Sede de Sevilla, Sección Segunda, del Tribunal Superior de Justicia de Andalucía, Sala de lo Contencioso-administrativo sobre la cuestión, se encuentran las siguientes:

- STSJ de Andalucía de 21 de septiembre de 2017, rec. núm. 724/2015. Ponente IImo. Sr. D. Luis G. Arenas Ibáñez. Interpuesto por Campo de Dalias, S. A. (ECLI: ES:TSJAND:2017:8835).

- STSJ de Andalucía de 21 de septiembre de 2017, rec. núm. 722/2015. Ponente Ilmo. Sr. D. Luis G. Arenas Ibáñez. Interpuesto por Gestión de Inmuebles, Viviendas y Patrimonio, S. L. (ECLI: ES:TSJAND:2017:8834).

- STSJ de Andalucía de 21 de septiembre de 2017, rec. núm. 712/2015. Ponente Ilmo. Sr. D. Luis G. Arenas Ibáñez. Interpuesto por el Ayuntamiento de Almuñecar (ECLI: ES:TSJAND:2017:8833).

- STSJ de Andalucía de 11 de octubre de 2017, rec. núm. 685/2015. Ponente Ilma. Sra. Dña. Marta Rosa López Velasco (ECLI: ES:TSJAND:2017:10319).

55 Precisamente al cierre del presente trabajo se ha dado a conocer la inadmisión a trámite del recurso de casación planteado frente al fallo de una de las Sentencias recaídas. Así se recoge en la Resolución de 23 de abril de 2018, de la Secretaría General Técnica, por la que se dispone el cumplimiento y publicación del fallo de la Sentencia de 7 de septiembre de 2017, de la Sección Segunda de la Sala de lo Contencioso-Administrativo del Tribunal Superior de Justicia de Andalucía, con sede en Sevilla (BOJA núm. 81, 27-04-2018).

56 Como ya acaeciera con el POTS de la Costa del Sol Occidental de la provincia de Málaga en el año 2015, son cuestiones formales las que determinan que la Sentencia del Tribunal Supremo, Sala de lo Contencioso-administrativo, de 6 de octubre de 2015, rec. núm. 2676/2012 (ECLI: ES:TS:2015:4382), falle su nulidad de pleno derecho. Sobre el particular ya se tuvo ocasión de analizar la importancia del estricto cumplimiento de los trámites procedimentales de los planes territoriales y sus nefastas consecuencias jurídicas.

En RANDO BURGOS, E. (2016): "La relevancia del procedimiento de tramitación de los instrumentos de planificación territorial: la nulidad del Plan de Ordenación del Territorio de la Costa del Sol de Málaga por la Sentencia del Tribunal Supremo de 6 de noviembre de 2015". En Actas VIII Congreso Internacional de Ordenación del Territorio, Fuerteventura, mayo 2016. Editado por Asociación Interprofesional de Ordenación del Territorio, Fundicot, Madrid, 2016, págs. 925-936.

57 En el rec. núm. 721/2015, los reproches jurídicos planteados por la recurrente y fundados en cuestiones de fondo, son: infracción del orden constitucional de competencias y del principio de jerarquía normativa, vulneración del principio de autonomía local, por el Decreto-ley 5/2012, de 27 de noviembre; desviación del objeto de protección territorial que le corresponde al Plan de Protección del Corredor del Litoral de Andalucía, en cuanto instrumento de ordenación del territorio no puede valerse de motivos paisajísticos y ambientales para establecer una protección específica en determinados ámbitos; ausencia en el estudio económico de partidas indemnizatorias, lo que ante la concurrencia de supuestos indemnizatorios, determinaría la nulidad del plan de protección; insuficiente valoración de las distintas alternativas razonables en el informe de sostenibilidad ambiental; falta de motivación en la protección territorial de superficies ubicadas por encima de los primeros quinientos metros de la zona de influencia del litoral; arbitrariedad en la adjudicación de la protección territorial vulneración del principio de equidad y de igualdad jurídica y de proporcionalidad. 


\subsection{Pronunciamiento del Tribunal Superior de Justicia de Andalucía}

La alegación de la actora se sustenta en la incompetencia del Gobierno de Andalucía en funciones para el dictado del Decreto objeto de impugnación, con fundamento en la doctrina de la Sentencia del Tribunal Supremo de 2 de diciembre de 2005, en la medida en que la aprobación del Decreto 141/2015, no es susceptible de ser calificada como una actuación de despacho ordinario, en cuanto comporta un evidente contenido o valor político, además de limitar el ejercicio de las funciones que le correspondería desarrollar al nuevo Gobierno, y habiéndose aprobado por el Gobierno de Andalucía en funciones, procede declarar la nulidad de pleno derecho del mismo, por vicio de incompetencia manifiesta.

Frente a ella, se alza la demandada (Junta de Andalucía), solicitando la desestimación de la demanda y alegando que el Decreto objeto de litis, en cuanto aprueba el PPCLA, carece de toda orientación política. Su formulación viene establecida por ley, exigiendo el legislador que su aprobación se produjera en dos años y seis meses, plazo que se encontraba próximo a vencer cuando el plan fue aprobado. Además, se alega que el interés general del PPCLA estaba justificado por la legislación vigente en materia de ordenación del territorio, que podría verse perjudicada por la no aprobación del plan en el plazo fijado.

\subsubsection{Sobre el marco jurídico de referencia}

Centrado, pues, el objeto del proceso en el enjuiciamiento de la posible falta de competencia del órgano autonómico para su aprobación, la Sentencia, con un pormenorizado análisis, parte del examen del régimen jurídico del Gobierno en funciones contenido en la CE, en la Ley del Gobierno, en el Estatuto de Autonomía de Andalucía y en la propia Ley de Gobierno de Andalucía.

Sobre la base de lo previsto en el art. 101 de la CE que establece que el Gobierno cesa tras la celebración de elecciones generales, en los casos de pérdida de la confianza parlamentaria previstos en la propia Constitución, o por dimisión o fallecimiento de su Presidente, continuando el Gobierno cesante en funciones hasta la toma de posesión del nuevo Gobierno, la Ley 50/1997, de 27 de noviembre, del Gobierno, desarrolla en su art. 21 la figura del Gobierno en funciones ${ }^{58}$.

A nivel autonómico, el Estatuto de Autonomía de Andalucía, aprobado por la Ley Orgánica 2/2007, de 19 de marzo, establece en su art. 120 que el Consejo de Gobierno cesa tras la celebración de elecciones al Parlamento, continuando en funciones hasta la toma de posesión del nuevo Consejo de Gobierno. Cuestión desarrollada por el art. 37 de la Ley 6/2006, de 24 de octubre, del Gobierno de Andalucía ${ }^{59}$.

58 Precepto cuyo tenor litoral, dispone:

1. El Gobierno cesa tras la celebración de elecciones generales, en los casos de pérdida de confianza parlamentaria previstos en la Constitución, o por dimisión o fallecimiento de su Presidente.

2. El Gobierno cesante continúa en funciones hasta la toma de posesión del nuevo Gobierno, con las limitaciones establecidas en esta Ley.

3. El Gobierno en funciones facilitará el normal desarrollo del proceso de formación del nuevo Gobierno y el traspaso de poderes al mismo y limitará su gestión al despacho ordinario de los asuntos públicos, absteniéndose de adoptar, salvo casos de urgencia debidamente acreditados o por razones de interés general cuya acreditación expresa así lo justifique, cualesquiera otras medidas.

4. El Presidente del Gobierno en funciones no podrá ejercer las siguientes facultades:

a) Proponer al Rey la disolución de alguna de las Cámaras, o de las Cortes Generales.

b) Plantear la cuestión de confianza.

c) Proponer al Rey la convocatoria de un referéndum consultivo.

5. El Gobierno en funciones no podrá ejercer las siguientes facultades:

a) Aprobar el Proyecto de Ley de Presupuestos Generales del Estado.

b) Presentar proyectos de ley al Congreso de los Diputados o, en su caso, al Senado.

6. Las delegaciones legislativas otorgadas por las Cortes Generales quedarán en suspenso durante todo el tiempo que el Gobierno esté en funciones como consecuencia de la celebración de elecciones generales.

59 Este artículo señala:

1. El Consejo de Gobierno cesa cuando cesa la persona titular de la Presidencia de la Junta de Andalucía.

2. El Consejo de Gobierno cesante continuará en funciones hasta la toma de posesión del nuevo Consejo de Gobierno.

3. El Gobierno en funciones facilitará el normal desarrollo del proceso de formación del nuevo Consejo de Gobierno y el traspaso de poderes al mismo, limitándose su gestión al despacho ordinario de los asuntos públicos de su competencia, salvo casos de urgencia o interés general debidamente acreditados.

4. El Presidente o la Presidenta en funciones de la Junta de Andalucía no podrá ser sometido o sometida a una moción de censura. Tampoco podrá ejercer las siguientes facultades:

a) Designar o separar a las personas titulares de las Vicepresidencias o de las Consejerías.

b) Crear, modificar o suprimir Vicepresidencias o Consejerías. 
Del marco jurídico de referencia, resulta indubitado que cuando en su sesión del día 26 de mayo de 2015, el Consejo de Gobierno aprueba el PPCLA, se encontraba en funciones, toda vez que el día 22 de marzo de 2015 había tenido lugar la celebración de elecciones autonómicas en Andalucía, convocadas por el Decreto 1/2015, de 26 de enero. Con posterioridad a aquéllas, con fecha 16 de abril se constituyó el Parlamento de Andalucía y no sería hasta apenas dos meses después, el 11 de junio, cuando tuviera lugar la investidura de la Presidenta, tomando posesión el 14 de junio.

El debate jurídico se centra en determinar sí la aprobación de un decreto encontrándose el Gobierno en funciones, se enmarca o no entre las facultades que le vienen reconocidas ${ }^{60}$.

\subsubsection{Sobre la doctrina jurisprudencial fijada por el Tribunal Supremo y la interpretación del concepto «despacho ordinario de asuntos»}

La CE se limita en su art. 101 a enumerar los supuestos en que el Gobierno cesa y a establecer una «prórroga» para el Gobierno cesante hasta que tiene lugar la toma de posesión del nuevo Gobierno, así señala en su aptdo. 2 que «continuando en funciones el Gobierno cesante hasta la toma de posesión del nuevo Gobierno». Ahora bien, esta particular situación cuenta con la limitación propia al no contar el Gobierno con la confianza de la nueva Cámara, aspecto desarrollado y concretado por la Ley 50/1997, del Gobierno, cuyo art. 21, trascribe dicho mandato en sus aptdos. 1 y 2 , incorporando a éste último precisamente el aspecto de las limitaciones.

En su apartado 3, el precepto recoge de manera general las atribuciones que le corresponde ejercer al Gobierno en funciones, en concreto tres, a saber, facilitar el normal desarrollo del proceso de formación del nuevo Gobierno y el traspaso de poderes, limitar su gestión al despacho ordinario de los asuntos públicos y abstenerse de adoptar "cualesquiera otras medidas», salvo en caso de urgencia debidamente acreditados o por razones de interés general. Frente a esta generalidad, sí que excluye expresamente dos facultades, enumeradas en el aptdo. 5 del propio art. 21, que no podrán ser realizadas por el Gobierno cuando se encuentre en esta particular situación: la aprobación del Proyecto de Ley de Presupuestos Generales del Estado y la presentación de Ley al Congreso de los Diputados o, en su caso, al Senado.

Y precisamente aquí, surge la controversia. El legislador opta por el empleo de conceptos jurídicos indeterminados a la hora de delimitar las atribuciones que corresponde desarrollar al Gobierno en funciones, a buen seguro con el claro propósito de poder integrar al conjunto de situaciones desconocidas que durante dicho período puedan tener lugar. Esta cuestión ya había sido objeto de debate previo y ha ido a lo largo de los años concretándose por los tribunales, doctrina jurisprudencial que la Sentencia acoge e incorpora.

En relación con la interpretación del aptdo. 3 del art. 21 de la Ley del Gobierno cuando señala «El Gobierno en funciones... limitándose su gestión al despacho ordinario de los asuntos públicos de su competencia, salvo casos de urgencia o interés general debidamente acreditados», la Sentencia hace un extenso análisis jurisprudencial de la doctrina del Tribunal Supremo, cuestión a la que dedica sus F. D. Quinto y Sexto.

En primer lugar, invoca la Sentencia del Tribunal Supremo de 20 de septiembre de 2005 que ya dispusiera sobre el particular, "...la gestión administrativa ordinaria ausente de valoraciones y decisiones en las que entren criterios políticos salvo que se motive debidamente la urgencia o las razones del interés general que justifique la adopción de medidas de otra naturaleza».

Por su parte, analiza la doctrina fijada por la Sentencia del Tribunal Supremo de 2 de diciembre de 2005 (rec. núm. 161/2004) $)^{61}$, alegada por la actora, en concreto la fijada en su F. D. Octavo, conforme a la cual

c) Disolver el Parlamento de Andalucía

d) Plantear la cuestión de confianza.

5. El Consejo de Gobierno en funciones no podrá ejercer las siguientes facultades:

a) Aprobar el proyecto de Ley del Presupuesto de la Comunidad Autónoma.

b) Presentar proyectos de ley al Parlamento de Andalucía.

60 Sobre el alcance de la intervención del Gobierno en funciones también se ha pronunciado la doctrina. En este sentido puede verse, entre otros, los trabajos de REVENGA SÁNCHEZ, M. (1988): "El Gobierno en funciones", Gobierno y administración en la Constitución/Dirección General del Servicio Jurídico del Estado, vol. 2, págs. 1.501-1.524; ÁLVAREZ CONDE, E. (1997): "El Gobierno en funciones", Documentación Administrativa, núm. 246-247 (septiembre 1996 - abril 1997), págs. 191-218; GUILLÉN LÓPEZ, E. (2002): El cese del gobierno y el gobierno en funciones en el ordenamiento constitucional español. Sevilla. Instituto Andaluz de Administración Pública; NARANJO DE LA CRUZ, R. (2001): "Las causas de cese del gobierno en el ordenamiento constitucional español", Cuestiones constitucionales de la Cátedra Fadrique Furió Ceriol, núm. 36-37, págs. 23-48.

61 Ha de advertirse que la doctrina del TS sobre el gobierno en funciones se contiene fundamentalmente en la STS del Pleno de la Sala Tercera de 2 de diciembre de 2005 (STS 8303/2005 - ECLI: ES:TS:2005:8303), que sigue la doctrina ya establecida en la STS 
REALA. Nueva Época - N. 10 , Octubre 2018 - ISSN: 1989-8975 - DOI: 10.24965/reala.v0i10.10518 - [Págs. 109-131]

La anulación del Plan de Protección del Corredor Litoral de Andalucía por el Tribunal Superior de Justicia de Andalucía: ¿nuevas...

Esther Rando Burgos

se reconoce que la Constitución, ciertamente, no establece de modo expreso límites o restricciones a la actuación del Gobierno en funciones pero facilita el criterio para distinguir cuáles son los «confines» en que ha de moverse, fuera de los casos en que la urgencia determine la necesidad de su intervención, ya que la habilitación para resolver sobre éstos últimos va implícita a su existencia. Criterio que, según la Sentencia, resulta de la propia función constitucional del Gobierno, ya que «...de la que ha de desempeñar el que está en plenitud de sus facultades tras haber completado el proceso de su formación. Esa función no es otra que la dirección de la política interior y exterior y, en estrecha relación con ella, la defensa del Estado. Esos son los cometidos con los que el artículo 97 de la Constitución... singulariza la función gubernamental y para cuya realización atribuye al órgano Gobierno la dirección de la Administración Civil y Militar y le encomienda la función ejecutiva y la potestad reglamentaria...». Además, se centra en analizar las funciones del Gobierno que se forma, como la dirección de la política general, misión principal del Gobierno y que trae causa del programa defendido ante el Congreso de los Diputados por el candidato a la Presidencia y que mereció el apoyo de su mayoría, conforme al artículo 99 de la CE, programa presentado ante los ciudadanos y que logró el apoyo de sus votos, pese a lo cual reconoce expresamente que «...ese marco político de actuación no queda definitivamente fijado en ese momento y puede suceder que, por distintas razones, el Gobierno llegue a apartarse en diversa medida de la línea aprobada en el momento de la investidura. El sistema parlamentario permite una actualización permanente de la relación de confianza a través de su normal desenvolvimiento o con el recurso a algunas instituciones previstas en la Constitución como el referéndum consultivo (artículo 92) o la cuestión de confianza (artículo 112)», para a renglón seguido reconocer que «...mientras persista la relación de confianza entre el Congreso de los Diputados y, a través de su Presidente, el Gobierno, a este corresponde la dirección política de España. Así, gobernar para la Constitución, es dirigir el país a partir de las orientaciones definidas por el Presidente del Gobierno (artículo 98.2 de la Constitución) con el apoyo de la mayoría parlamentaria formada democráticamente por los españoles».

A sensu contrario, tras analizar lo que debe hacer el Gobierno que se forma, señala que es precisamente lo que, al mismo tiempo, no puede hacer el Gobierno en funciones ya que el cese ha interrumpido la relación de confianza que le habilita para ejercer tal dirección, concluyendo que «...el Gobierno en funciones ha de continuar ejerciendo sus tareas sin introducir nuevas directrices políticas ni, desde luego, condicionar, comprometer o impedir las que deba trazar el que lo sustituya. El cese priva a este Gobierno de la capacidad de dirección de la política interior y exterior a través de cualquiera de los actos válidos a ese fin, de manera que será preciso examinar, caso por caso, cuando surja controversia al respecto, si el discutido tiene o no esa idoneidad en función de la decisión de que se trate, de sus consecuencias y de las circunstancias en que se deba tomar».

De particular significancia, el F. D. Séptimo, en que la Sentencia, continuando con la doctrina fijada por la Sentencia del Tribunal Supremo de 2 de diciembre de 2005, se centra en precisar qué ha de entenderse por «despacho ordinario de asuntos» conforme al propio art. 21.3 de la Ley del Gobierno.

Partiendo de su carácter de concepto jurídico indeterminado, se destaca la necesidad de concreción, sobre la base del entendimiento que "...ese despacho no es el que no comporta valoraciones políticas o no implica ejercicio de discrecionalidad. Tampoco el que versa sobre decisiones no legislativas, sino el que no

de 20 de septiembre de 2005 (STS 5369/2005 - ECLI: ES:TS:2005:5369).

De esta forma, en la STS de 20 de septiembre de 2005, el TS establece que «Después del cese, la actividad gubernamental debe respetar una serie de restricciones. Aunque la Constitución no dice nada sobre sus posibles limitaciones, pues el artículo 101.2 señala que "el Gobierno cesante continúa en funciones hasta la toma de posesión del nuevo Gobierno", la práctica constitucional limitó su gestión a los asuntos de trámite... Hoy, la Ley 50/1997, de 27 de noviembre, en su título IV, trata de las competencias que corresponden al Gobierno en funciones y en su artículo 21, que desarrolla el artículo 101 de la Constitución, se completa y establece, según se constata del Diario de Sesiones del Congreso de los Diputados, una serie de requisitos y limitaciones, en el entendimiento de tener un tratamiento coherente de lo que es la fiducia quebrada entre las Cortes Generales y un Gobierno en funciones y la no pervivencia de determinados órganos de control que permitan establecer un control estable... El número 3 del citado artículo 21, de acuerdo con los principios establecidos en su exposición de motivos, precisa que "limitará su gestión al despacho ordinario de los asuntos, absteniéndose de adoptar, salvo casos de urgencia debidamente acreditados o por razones de interés general cuya acreditación expresa así lo justifique, cualesquiera otras medidas", teniendo en cuenta que, como dice la exposición de motivos, "el objetivo último de toda su actuación radica en la consecución de un normal desarrollo del proceso de formación del nuevo Gobierno"...», lo que interpreta en el sentido expresado en su F. D. Cuarto "La gestión administrativa ordinaria ausente de valoraciones y decisiones en las que entren criterios políticos salvo que se motive debidamente la urgencia o las razones de interés general que justifiquen la adopción de medidas de otra naturaleza».

De manera más reciente, las SSTS de 27 de diciembre de 2017 (STS 4743/2017 - ECLI: ES:TS:2017:4743), 27 de febrero de 2018 (STS 627/2018 - ECLI: ES:TS:2018:627) o 20 de marzo de 2018 (STS 935/2018 - ECLI: ES:TS:2018:935), mantienen la doctrina fijada en la STS de 2 de diciembre de 2005, a la que se remiten. 
REALA. Nueva Época - N. ${ }^{10}$ 10, Octubre 2018 - ISSN: 1989-8975 - DOI: 10.24965/reala.v0i10.10518 - [Págs. 109-131]

La anulación del Plan de Protección del Corredor Litoral de Andalucía por el Tribunal Superior de Justicia de Andalucía: ¿nuevas...

Esther Rando Burgos

se traduce en actos de orientación política...» lo que a entender de la meritada resolución judicial despeja las dudas que pudiera ofrecer la conformidad con el texto constitucional de las normas legales que sujetan a límites la actuación del Gobierno en funciones cuando aquél no ha dispuesto expresamente ninguno. Y en este contexto, es el legislador el que asume esa interpretación, lo que según el Tribunal Supremo, se deduce de los propios aptdos. 5 y 6 del art. 21, el primero al preocuparse por prohibir al Gobierno en funciones aprobar el proyecto de Ley de Presupuestos Generales del Estado y presentar proyectos de Ley al Congreso de los Diputados, lo que interpreta en el sentido que "...la Ley prohíbe al Gobierno en funciones utilizar los principales instrumentos de orientación política» y, el segundo, al dejar en suspenso las delegaciones legislativas mientras el Gobierno esté en funciones por haberse celebrado elecciones generales.

Y precisamente estas circunstancias refuerzan, al entender del Alto Tribunal, la necesidad de examinar caso por caso y asunto por asunto los que han de considerarse incluidos en el despacho ordinario y los que, por quedar fuera de él, no pueden ser abordados por el Gobierno en funciones de no existir urgencia o demandarlo el interés general contemplado en el art. 21.3. de la Ley del Gobierno. Lo que lleva a la conclusión de que la línea divisionaria entre lo que el Gobierno en funciones puede y no puede hacer no pasa por la distinción entre actos legislativos y no legislativos, sino por la diferenciación entre actos que conllevan dirección política y los que la expresan. Y concluye, tratando de precisar y fijar las pautas para la correcta interpretación del concepto «despacho ordinario de asuntos», que "En definitiva, el despacho ordinario de los asuntos público comprende todos aquellos cuya resolución no implique el establecimiento de nuevas orientaciones políticas ni signifique condicionamiento, compromiso o impedimento para las que debe fijar el nuevo Gobierno. Y esa cualidad que excluye a un asunto del despacho ordinario ha de apreciarse caso por caso, atendiendo a su naturaleza, a las consecuencias de la decisión a adoptar y al concreto contexto en que deba producirse»

Por último, en su propio F. D. Séptimo, cita la Sentencia del Tribunal Supremo de 28 de mayo de 2013 (núm. rec. 231/2012) que reitera la misma doctrina fijada a la vez que señala que ésta debe extenderse a las disposiciones de carácter general, carácter del que participan los instrumentos de ordenación urbanística y territorial. Como particularidad, esta última Sentencia citada que, en efecto acoge la doctrina del Tribunal Supremo, si bien entendió que la aprobación del Real Decreto 1744/2011, de 25 de noviembre, por el que se modificaba el Real Decreto 641/2009, de 17 de abril, regulador de los procesos de control de dopaje y los laboratorios de análisis autorizados, y por el que se establecen medidas complementarias de prevención del dopaje y de protección de la salud en el deporte, aun habiendo tenido lugar mientras el Gobierno se encontraba en funciones (fue aprobado el día 25 de noviembre de 2011, habiéndose celebrado elecciones generales el día 20 de ese mismo mes y año), su aprobación se enmarcaba dentro del ámbito del concepto jurídico indeterminado definido con la expresión "despacho ordinario de los asuntos públicos», sin necesidad por tanto de que al decidirla concurriera una situación de "urgencia» o una razón de «interés general», pues entendió entonces que no se percibía «nuevas orientaciones políticas» o «condicionamiento, compromiso o impedimento» para el nuevo Gobierno.

\subsubsection{Sobre la interpretación de la Sala de lo Contencioso-administrativo del TSJ de Andalucía}

Concretada pues, la interpretación del concepto «despacho ordinario de asuntos», la Sala entiende que en la aprobación del Decreto 141/2015 no concurría el mismo, considerando que su aprobación era una decisión que excedía del despacho ordinario de los asuntos públicos de competencia de un Gobierno en funciones.

Tal conclusión la motiva en los F. D. Octavo y Noveno. Para la Sala, el PPCLA constituye un ejercicio de la potestad normativa atribuida constitucional y estatutariamente al Gobierno autonómico que implica de «manera palmaria» el establecimiento de una nueva orientación política, en la medida en que el plan se aparta «...consciente y públicamente de los planes de ordenación de ámbito subregional ya existentes y en vigor e incluso del Plan de Ordenación del Territorio de Andalucía, alterando radicalmente los objetivos y la finalidad de la política territorial en el ámbito del litoral andaluz y, consecuentemente, modificando de manera sustancial las directrices y determinaciones de dichos instrumentos».

Pero además, la Sentencia llega a afirmar que el PPCLA supone un cambio de modelo. Este entendimiento como nueva orientación política tiene una consecuencia inmediata, "...implica un condicionamiento, compromiso o impedimento para la potestad de dirección política del nuevo Gobierno, desde el punto de vista estrictamente jurídico y objetivo», pese a que, como expresamente reconoce, el nuevo Gobierno está sustentado por el mismo partido político. 
REALA. Nueva Época - N. ${ }^{0}$ 10, Octubre 2018 - ISSN: 1989-8975 - DOI: 10.24965/reala.v0i10.10518 - [Págs. 109-131]

La anulación del Plan de Protección del Corredor Litoral de Andalucía por el Tribunal Superior de Justicia de Andalucía: ¿nuevas..

Esther Rando Burgos

Incluso, avanzando en la tesis expuesta, la Sala en el F. D. Octavo in fine, concluye que «...el PPCLA como instrumento jurídico de realización de la planificación del territorio, es la expresión espacial de la política económica, social, cultural y ecológica de la sociedad en el corredor litoral de Andalucía. Es perspicuo que el PPCLA asume la orientación política general de ordenación del territorio, por ser un instrumento de ordenación territorial previsto en la Ley 1/1994 y, especialmente, contiene sus propias directrices políticas de protección del corredor litoral». Cuestiones éstas que sustenta en la propia documentación integrante del PP. CLA, en concreto en la Memoria Informativa y en la Memoria de Ordenación, y que aborda en el F. D. Noveno.

En relación con la Memoria Informativa del PPCLA, la Sala transcribe el contenido de su introducción, en que indica "...el presente Plan de Protección del Corredor Litoral de Andalucía tiene como propósito desarrollar los contenidos que para el mismo establece la Ley 1/1994, de 11 de enero, de Ordenación del Territorio de Andalucía, modificada por el Decreto-Ley, de 27 de noviembre, de medidas urgentes en materia urbanística y para la protección del litoral de Andalucía... el Plan de Protección del Corredor Litoral centra su atención en la franja costera, el espacio más tensionado del litoral, al objeto de establecer un tratamiento integrado que permita compatibilizar el desarrollo de un ámbito que se considera esencial para nuestro sistema productivo, con su sostenibilidad económica y ambiental».

A la par que, centrada en los objetivos generales del PPCLA, y atendiendo a lo dispuesto en el apartado 1. Objetivos de la Memoria de Ordenación, la Sentencia entiende que éstos abundan en el entendimiento que contiene, así transcribe los objetivos generales recogidos en el referido documento, centrados, como se indicaba líneas atrás, en la necesidad de establecer criterios y determinaciones para la protección, conservación y puesta en valor de las zonas costeras andaluzas desde objetivos de perdurabilidad y sostenibilidad. Objetivo general que se desarrolla a través de cinco objetivos específicos, como también transcribe "...1. Preservar de la urbanización las zonas con valores ambientales, naturales, paisajísticos, culturales, agrícolas y forestales de los espacios litorales; 2. Evitar la consolidación de nuevas barreras urbanas entre los espacios interiores y los del sistema litoral; 3. Armonizar la regulación del suelo no urbanizable en el ámbito del Plan; 4. Favorecer la biodiversidad a través de continuidad de los espacios del interior con el litoral; 5. Propiciar el mantenimiento del litoral como recurso turístico básico evitando su consolidación con nuevos usos residenciales estacionales».

Consecuencia de todo ello, es el desarrollo de los anteriores objetivos a través de actuaciones de consecuencias de diversa índole: urbanísticas (con la finalidad de evitar la consolidación de un continuo edificado que podría llegar a cubrir una parte sustancial de la línea de costas y armonizar la regulación de suelo no urbanizable estableciendo los criterios y directrices para su preservación); patrimoniales (cuyo objeto es preservar los espacios costeros por sus valores paisajísticos, naturales y culturales); y ambientales (cuyo fin es posibilitar la preservación del medio costero y asegurar la continuidad entre los ecosistemas terrestres y marítimos).

Estas cuestiones reafirman, como recoge el F. D. Décimo de la Sentencia, el entendimiento que sostiene, esto es, en la medida en que "...el PPCLA asume la orientación política en general de ordenación del territorio, y especialmente, en la medida en que su normativa contiene sus propias directrices políticas para regular la actividad de gobierno de protección del corredor litoral andaluz», la conclusión en consonancia con la doctrina del Tribunal Supremo, es «...que el Decreto 141/2015, de 26 de mayo, de aprobación definitiva del Plan de Protección del Corredor del Litoral de Andalucía, no puede considerarse despacho ordinario de asuntos públicos, debido a que por su clara y meridiana orientación política y su vocación y proyección de futuro, excede del indicado concepto y condiciona y compromete al nuevo Gobierno, con independencia de que el nuevo Gobierno, estuviese sustentado por el mismo partido político, sin que pueda ampararse la aprobación en la naturaleza de disposición general del instrumento de ordenación y en el interés general que en abstracto ostentan las disposiciones generales, en la medida en que el indicado interés general no sufriría por demorarse la aprobación escasamente un mes, hasta la toma de posesión del nuevo gobierno...».

Tampoco entiende la Sala que el hecho de que la formulación y aprobación del PPCLA viniese impuesta por el legislador, en concreto en la LOTA, constituya motivo para eliminar la orientación política de la aprobación del instrumento, bien al contrario, considera que lejos de enervar la orientación política, la reafirma, toda vez que, como señala la Sentencia en su F. D. Décimo, "...el PPCLA como instrumento jurídico de realización de la planificación del territorio, es la expresión espacial de la política económica, social, cultural y ecológica de la sociedad en el corredor litoral de Andalucía ... el PPCLA asume la orientación política en general de ordenación del territorio, por ser un instrumento jurídico previsto en la Ley 1/1994 y, especialmente, contiene directrices políticas de protección del litoral. Por tanto, la previsión en la Ley 1/1994 de 
REALA. Nueva Época - N. ${ }^{10}$ 10, Octubre 2018 - ISSN: 1989-8975 - DOI: 10.24965/reala.v0i10.10518 - [Págs. 109-131]

La anulación del Plan de Protección del Corredor Litoral de Andalucía por el Tribunal Superior de Justicia de Andalucía: ¿nuevas...

Esther Rando Burgos

\section{la aprobación y formulación del PPCLA, que en su propia orientación política es autónomo, por lo que la referida previsión en la Ley 1/1994, lejos de enervar las orientaciones políticas, lo que hace es reafirmarlas».}

Desde el entendimiento anterior, resulta cuestionable, al menos, desde un punto de vista del análisis formal del instrumento, como lo hace la Sentencia, la afirmación contenida en sus F. D. Octavo y Noveno, conforme a la cual, el PPCLA constituye un ejercicio de la potestad normativa atribuida constitucional y estatutariamente al Gobierno autonómico que implica de «manera palmaria» el establecimiento de una nueva orientación política, en la medida en que el plan se aparta consciente y públicamente de los planes de ordenación de ámbito subregional ya existentes y en vigor e incluso del Plan de Ordenación del Territorio de Andalucía, alterando radicalmente los objetivos y la finalidad de la política territorial en el ámbito del litoral andaluz y, consecuentemente, modificando de manera sustancial las directrices y determinaciones de dichos instrumentos.

Sobre este particular, parece adecuado detenerse. La determinación del modelo territorial para el conjunto autonómico viene, como se indicaba, atribuido al POTA, así el art. 6 de la LOTA le confiere la potestad para establecer los elementos básicos para la organización y estructura del territorio de la Comunidad Autónoma, siendo, además, el marco de referencia territorial para los demás planes regulados en la propia ley, esto es, el propio PPCLA y los POTS, así como para los Planes con Incidencia en la Ordenación del Territorio, e incluso para la acción pública en general. Este aspecto, se vuelve a evidenciar en el propio art. 42 de la LOTA, así en su aptdo. 1, al PPCLA le viene atribuido establecer objetivos, criterios y determinaciones para la protección, conservación y puesta en valor de las zonas costeras de Andalucía, si bien con un límite: en el marco de lo establecido en el Plan de Ordenación del Territorio de Andalucía para el dominio litoral.

A mayor abundamiento, el marco en que ha de desarrollarse el PPCLA debe someterse a las propias previsiones del POTA, instrumento por el que resulta vinculado a tenor del propio art. 22 de la LOTA, que sitúa a éste en la cúspide del sistema de jerarquía de los instrumentos.

En consecuencia, modificar de manera sustancial, como se llega a afirmar por la Sentencia, las directrices y determinaciones del POTA conllevaría la vulneración del principio de jerarquía normativa y del principio de legalidad, ambos consagrados en el art. 9.3 de la CE.

\subsubsection{Sobre la posible concurrencia de razones de urgencia o de interés general en la aprobación del PPCLA}

Partiendo del entendimiento de que la aprobación del PPCLA constituye una decisión que excede lo que, conforme a la doctrina fijada por el Tribunal Supremo, ha de interpretarse por despacho ordinario de los asuntos públicos que puede llevar a cabo un Gobierno en funciones, la Sentencia dedica sus F. D. Undécimo, Duodécimo y Decimotercero, a valorar la posible concurrencia de razones de urgencia o de interés general en el Decreto aprobado, lo que conforme a lo previsto en el propio art. 21.3 de la Ley del Gobierno, pudiera amparar la aprobación del plan.

Pues bien, la conclusión que sobre esta cuestión tiene la Sala insiste nuevamente en lo hasta aquí analizado: no concurrían concretas razones de urgencia o interés general que, en su caso, hubiesen amparado la aprobación del PPCLA por el Gobierno en funciones, y todo ello pese a su contenido político.

Aunque, según se desprende del F. D. Undécimo, obraba en el expediente administrativo un informe de 25 de mayo de 2015 de la Secretaría General de Ordenación del Territorio y Cambio Climático, en el que se aducen razones de urgencia e interés general relativas a la aprobación del PPCLA por el Consejo de Gobierno, esto no hace más que, al entender de la Sala, corroborar el convencimiento de la propia Administración del carácter político que revestía la aprobación del instrumento a la par que el reconocimiento expreso de las limitaciones que para la adopción de acuerdos tenía en ese momento el Consejo de Gobierno. Las concretas razones de urgencia e interés general aducidas en el citado informe, conforme a la meritada Sentencia, son:

«1) La elaboración del Plan se ha llevado a cabo conforme a los trámites preceptivos establecidos en las normas de aplicación y se encuentra actualmente ultimada, pendiente exclusivamente del acto de aprobación por el Consejo de Gobierno, todo ello en el plazo de dos años y seis meses legalmente establecido.

2) Razones de urgencia justifican la aprobación antes del 27 de mayo de 2015, fecha límite del plazo fijado, ya que de otro modo se estaría incumpliendo una disposición legal con las consecuencias jurídicas que de ello pudieran derivarse respecto de la nulidad del Plan en un posible recurso contencioso administrativo. 
3) De otra parte, la no aprobación del Plan en el plazo fijado motivaría el levantamiento de la suspensión cautelar establecida por el Decreto Ley 5/2012, de 27 de noviembre, respecto de la aprobación de instrumentos de planeamiento de desarrollo en zonas protegidas por el nuevo instrumento, lo que incrementaría los gastos derivados de posibles indemnizaciones en el caso de aprobarse el Plan con posterioridad, en los siguientes supuestos:

- Sectores de suelo urbanizable sin Plan Parcial aprobado que podrían iniciar su tramitación, con un total de 46 sectores (30 sectorizados y 16 no sectorizados), una superficie aproximada de 2000 hectáreas con capacidad para unas 31.000 viviendas.

- Sectores de suelo urbanizable con Plan Parcial aprobado, a los que si bien no les afecta la suspensión, podrían iniciar materialmente su ejecución. Esto sería el caso de los Planes Parciales de Valdevaqueros y Los Lances en Tarifa y El Cañar y el Camillar en Carboneras, próximos al "El Algarrobico", ubicados todos en zonas de gran valor ambiental.

4) En definitiva, la no aprobación del Plan de Protección del Corredor Litoral de Andalucía, en el plazo legalmente establecido dejaría sin efecto el objeto de salvaguardar intereses generales sujetos a la tutela de la Comunidad Autónoma presentes en este ámbito, ya que impediría la protección y puesta en valor de la franja costera e imposibilitaría un desarrollo urbanístico sostenible adecuado a la capacidad de acogida del territorio.».

Motivos, todos ellos, que al parecer de la Sala no son suficientes para justificar la aprobación del PPCLA. Pero además, a mayor abundamiento, insiste en que ni siquiera (y pese a, debe insistirse, ser conocidos por la Administración y constar un informe en el que se ponía de manifiesto) fueron objeto de motivación in alliunde o per relationem en el documento de aprobación del plan, lo que sin duda no hubiera generado mayor complejidad al constar expresamente en el expediente de tramitación del PPCLA.

Sobre las premisas anteriores, la Sala concluye en su F. D. Decimotercero que el Decreto 141/2015, de 26 de mayo, que aprueba el PPCLA «....no menciona ni justifica razón alguna de urgencia o interés general que motivaran la aprobación por el Gobierno en Funciones, tal y como exige el art. 37 de la Ley 6/2006. "No sólo no justifica la aprobación en las indicadas razones, sino que ni tan siquiera menciona, remite o reenvía al contenido del informe de 25 de mayo de 2015, de la Secretaría General de Ordenación del Territorio y Cambio Climático"», abundando en la idea que recoge expresamente, «"las razones de urgencia y de interés general que contiene el mentado informe de 25 de mayo de 2015", recogidas en el fundamento de derecho undécimo de la presente sentencia, "no se sostienen jurídicamente". No puede justificarse como razón de urgencia la aprobación antes del 27 de mayo de 2015, fecha límite del plazo fijado (2 años y 6 meses), ya que de otro modo se estaría incumpliendo una disposición legal con las consecuencias jurídicas que de ello pudieran derivarse respecto de la nulidad del Plan en un posible recurso contencioso administrativo....».

Además, analiza el instituto de la caducidad en la aprobación de planes territoriales, en referencia a las consecuencias que, aducidas por la demandada, se habían producido por la aprobación «tardía» del instrumento, con remisión a la doctrina fijada por el Tribunal Supremo, entre otras, en Sentencia de 8 de marzo de 2012, que estimando el recurso de casación interpuesto por la Junta de Andalucía, contra la Sentencia de 6 de marzo de 2008, de la propia Sala sentenciadora, estimó el recurso que, en la instancia, había declarado la nulidad del Decreto por el que se aprobó el Plan de Ordenación del Territorio del Litoral Occidental de Huelva, recordando que la caducidad «...no es aplicable a los instrumentos de ordenación que participan de la naturaleza de disposiciones de carácter general».

Finalmente, la Sala procede a estimar el recurso planteado, sustentado en «la falta de competencia del Gobierno en funciones para la aprobación del PPCLA, lo que conlleva la nulidad de pleno derecho del Decreto 141/2015, de 26 de mayo de conformidad con lo dispuesto en el art. 62.1.b) de la Ley 30/1992, de 26 de noviembre, entonces vigente».

\section{REFLEXIONES FINALES}

A modo de conclusiones, es adecuado detenerse en un conjunto de aspectos que la Sentencia del Tribunal Superior de Justicia de Andalucía, Sala de lo Contencioso-administrativo, de 7 de septiembre de 2017, vuelven a poner de actualidad, pese a que no son ni mucho menos, una novedad. 
REALA. Nueva Época - N. ${ }^{10}$ 10, Octubre 2018 - ISSN: 1989-8975 - DOI: 10.24965/reala.v0i10.10518 - [Págs. 109-131]

La anulación del Plan de Protección del Corredor Litoral de Andalucía por el Tribunal Superior de Justicia de Andalucía: ¿nuevas...

Esther Rando Burgos

La nulidad del PPCLA vuelve a poner encima de la mesa un espinoso tema que no es, por desgracia, exclusivo de Andalucía como tampoco lo es de la planificación territorial. Desde hace años, a la compleja labor que supone la aprobación de un instrumento de planificación territorial, se suma un segundo «filtro», la revisión por nuestros tribunales. Con la doctrina jurisprudencial actual puede devenir casi en una «misión imposible» pero lo que es peor, puede tardar años en llegar. En suma, la nulidad del PPCLA es consecuencia de la doctrina jurisprudencial reiterada del Tribunal Supremo que mantiene la consideración de disposición de carácter general de los planes y con ello la aplicación de lo dispuesto en el ya derogado art. 62.2 de la Ley 30/1992 y hoy regulado en el art. 47.2 de la Ley 39/2015, de Procedimiento Administrativo Común de las Administraciones Públicas, lo que lleva a que cualquier vulneración, sea de fondo o de forma, en el plan, tiene la misma consecuencia jurídica: su nulidad de pleno derecho.

Consecuencia de lo anterior, es que se desconoce la idoneidad o no del modelo por el que apuesta el PPCLA, ya que precisamente al ser una cuestión formal la que determina su nulidad, se imposibilita entrar al fondo del instrumento lo que, en su caso, posibilitaría un pronunciamiento sobre este particular. Este hecho se viene reiterando en el tiempo en los diferentes instrumentos, tanto territoriales como urbanísticos, que anulados por aspectos formales no son enjuiciados en relación a los modelos, propuestas, objetivos y directrices que plantean, esta cuestión podría dar lugar a que, tramitados y aprobados de nuevo y, salvado el escollo de las posibles vulneraciones formales, se enfrentasen a un cuestionamiento en cuanto al fondo. Si a lo anterior, se añade los largos períodos temporales que requiere la tramitación y aprobación de cualquier instrumento de estas características y la conocida lentitud del orden contencioso-administrativo, nos encontramos ante un problema de seguridad jurídica de los planes que afecta no sólo a la Administración competente, sino también a otras tantas que quedan vinculadas por lo allí establecido, y junto a éstas, a la ciudadanía en general.

De manera particular, la Sentencia analizada, sustenta su fallo en la doctrina señalada que a la postre centra el debate en la interpretación de lo que la propia resolución judicial reconoce como concepto jurídico indeterminado, qué ha de entenderse o qué integra el concepto «despacho ordinario de asuntos». Al margen de la oportunidad e incluso conformidad con el modelo planteado por el PPCLA, la cuestión que nuevamente subyace son los efectos que la nulidad de un plan acarrea y las trabas que supone para el logro del modelo territorial en el que traen causa, lo que vuelve a poner encima de la mesa el debate sobre la necesidad de modular la doctrina mantenida sobre la nulidad y anulabilidad de los planes, territoriales o urbanísticos, y sus efectos desproporcionados, frente a las cada vez mayores voces que plantean la necesidad de la subsanación y conservación de trámites.

Cuestión distinta, debe insistirse, sería sí el fallo se sustentará en el fondo del modelo planteado por el PPCLA y su posible, como también apunta la Sentencia analizada, afectación a los objetivos y la finalidad de la política territorial en el ámbito del litoral andaluz por apartarse de los POTS preexistentes e incluso del propio POTA.

\section{BIBLIOGRAFÍA}

ÁLVAREZ CONDE, E. (1997): "El Gobierno en funciones", Documentación Administrativa, núm. 246-247 (septiembre 1996-abril 1997), págs. 191-218.

BARRAGÁN MUÑOZ, J. M. (1993): "Perspectiva regional de la ordenación, planificación y gestión del espacio litoral. El caso andaluz", Revista de Estudios Regionales, núm. 37, págs. 129-138.

BENABENT F. DE CÓRDOBA, M. (2006): La Ordenación del Territorio en España: evolución del concepto y de su práctica en el siglo XX. Sevilla: Consejería de Obras Públicas y Transportes de la Junta de Andalucía y Universidad de Sevilla.

HILDENBRAND SCHEID, A. (1996): Política de Ordenación del Territorio en Europa. Sevilla: Universidad de Sevilla. Consejería de Obras Públicas y Transportes.

HILDENBRAND SCHEID, A. (2002): "La política territorial de la Junta de Andalucía (1982-2002). Análisis de su implementación, balance y propuestas". Ponencia XX Aniversario del Estatuto de Autonomía de Andalucía. Jornadas de Estudio organizadas por el Parlamento de Andalucía, Jerez de la Frontera, 6, 7 y 8 de marzo de 2002.

GONZÁLEZ FUSTEGUERAS, M. A. (2017): "Luces y sombras de la ordenación del territorio en Andalucía. Nuevas perspectivas", Práctica urbanística: Revista mensual de urbanismo, núm. 147 (Ejemplar dedicado a: La ordenación del territorio en Andalucía).

GUILLÉN LÓPEZ, E. (2002): El cese del gobierno y el gobierno en funciones en el ordenamiento constitucional español. Sevilla: Instituto Andaluz de Administración Pública. 
LA CALLE, A. (2013): "Derecho y políticas ambientales en Andalucía”, Revista Catalana de Dret Ambiental, vol. IV, núm. 1, págs. 1-14.

MARTÍN VALDIVIA, S. M. (2013): "La protección del litoral andaluz y otras medidas de urgencia: entre la necesidad y el oportunismo". Revista de Urbanismo y Edificación, núm. 27, págs. 51-89.

NARANJO DE LA CRUZ, R. (2001): "Las causas de cese del gobierno en el ordenamiento constitucional español", Cuestiones constitucionales de la Cátedra Fadrique Furió Ceriol, núm. 36-37, págs. 23-48.

NúÑEZ LOZANO, M. C. (2016): Estudios Jurídicos sobre el litoral. Tirant Lo Blanch.

PÉREZ ANDRES, A. A. (1998): La ordenación del territorio en el estado de las autonomías. Marcial Pons.

RANDO BURGOS, E. (2016): "La relevancia del procedimiento de tramitación de los instrumentos de planificación territorial: Ia nulidad del Plan de Ordenación del Territorio de la Costa del Sol de Málaga por la Sentencia del Tribunal Supremo de 6 de noviembre de 2015", en Actas VIII Congreso Internacional de Ordenación del Territorio, Fuerteventura, mayo 2016. Editado por Asociación Interprofesional de Ordenación del Territorio, Fundicot, Madrid, 2016, págs. 925-936.

RANDO BURGOS, E. (2018a): Áreas de oportunidad y ordenación del territorio en Andalucía. Inédito, pendiente de publicación. Sevilla. Instituto Andaluz de Administración Pública. Junta de Andalucía.

RANDO BURGOS, E. (2018b): "La atención al medio ambiente desde la ordenación del territorio: una visión general desde el marco legislativo autonómico". Actualidad Jurídica Ambiental, núm. 81, julio 2018, págs. 121-156. Disponible http://www.actualidadjuridicaambiental.com/comentario-legislativo-la-atencion-al-medio-ambientedesde-la-ordenacion-del-territorio-una-vision-general-desde-el-marco-legislativo-autonomico/.

REVENGA SÁNCHEZ, M. (1988): "El Gobierno en funciones", Gobierno y administración en la Constitución. Dirección General del Servicio Jurídico del Estado, vol. 2, págs. 1.501-1.524.

RODRÍGUEZ VIDAL, J. y NUÑEZ LOZANO, M. C. (2015): Litoral de Andalucía: normas y naturaleza. Huelva: Universidad de Huelva.

SERRANO LÓPEZ, J. E. y SERRANO MORENO, J. E. (2016): "La (in)sostenibilidad económica y financiera del plan de protección del corredor litoral de Andalucía", Revista de Derecho Urbanístico y Medio Ambiente, núm. 306, Madrid, junio (2016), págs. 69-103.

ZAMORANO WISNES, J. (2013): "Comentarios al Decreto-Ley 5/2012 de medidas urgentes en materia urbanística y para la protección del litoral de Andalucía”, Administración de Andalucía: Revista Andaluza de Administración Pública, págs. 149-186.

- (2016): "La ordenación del litoral en Andalucía. El Plan de Protección del Corredor Litoral de Andalucía”, en NÚÑEZ LOZANO, M. C. (dir.), Estudios Jurídicos sobre el litoral, Tirant Lo Blanch, págs. 87-130.

ZOIDO NARANJO, F. (2011): “Ordenación del territorio en Andalucía”, Cuadernos Geográficos, núm. 47 (2010-2), págs. 189-221.

\section{Otras fuentes}

CONSEJERÍA DE MEDIO AMBIENTE Y ORDENACIÓN DEL TERRITORIO, Junta de Andalucía (página web). Disponible en http://www.juntadeandalucia.es/medioambiente/site/portalweb/menuitem.6ffc7f4a4459b86a1daa5c1 05510 e1 ca/?vgnextoid $=b 45 e 6 b 7$ bf3d34510VgnVCM2000000624e50aRCRD. 